\title{
PADRÕES DE MODERNIZAÇÃO NA AGROPECUÁRIA BRASILEIRA EM 2006
}

\author{
Rodrigo Peixoto da Silva * \\ Carlos Eduardo de Freitas Vian ${ }^{\dagger}$
}

\begin{abstract}
Resumo
Este trabalho estabeleceu 9 clusters de municípios brasileiros com base em 30 indicadores de modernização agropecuária e os classificou de acordo com suas condições produtivas. Os resultados indicam forte heterogeneidade no meio rural. Mais da metade dos estabelecimentos agropecuários se enquadra nos três clusters mais vulneráveis, com condições produtivas precárias. Eles se concentram nas regiões Norte e Nordeste e representam apenas $25 \%$ do PIB agropecuário. Por outro lado, os três clusters mais modernos representam $19 \%$ dos estabelecimentos, $12 \%$ da área utilizável e $22 \%$ do emprego rural, mas representam 32\% do PIB agropecuário e se concentram nas regiões Sul e Sudeste.
\end{abstract}

Palavras-chave: análise de clusters, heterogeneidade, agropecuária. Códigos JEL: Q16, Q18, C38.

\begin{abstract}
This work established 9 clusters of Brazilian municipalities based on 30 indicators of agricultural modernization and classified them according to their productive conditions. Results indicated strong heterogeneity in rural areas. More than half of agricultural establishments fall into the three most vulnerable clusters, with poor productive conditions. They are concentrated in the North and Northeast and represent only $25 \%$ of agricultural GDP. On the other hand, the three most modern clusters represent $19 \%$ of establishments, $12 \%$ of arable area and $22 \%$ of rural employment, but represent $32 \%$ of agricultural GDP and are concentrated in the South and Southeast.
\end{abstract}

Keywords: cluster analysis, heterogeneity, agriculture.

JEL codes: Q16, Q18, C38.

DOI: http://dx.doi.org/10.11606/1980-5330/ea160541

\footnotetext{
* Doutor em Economia Aplicada pela Escola Superior de Agricultura Luiz de Queiroz Universidade de São Paulo - ESALQ/USP; Pesquisador associado ao Instituto de Pesquisa Econômica Aplicada (IPEA - desde dezembro de 2020) e ao Centro de Estudos Avançados em Economia Aplicada (CEPEA - ESALQ/USP). E-mail: rodrigo.peixoto@hotmail.com

† Professor Doutor do Departamento de Economia, Administração e Sociologia da Escola Superior de Agricultura Luiz de Queiroz Universidade de São Paulo - ESALQ/USP. E-mail: cefvian@usp.br
} 


\section{Introdução}

A modernização agropecuária brasileira foi bastante discutida pela literatura econômica na década de 1980, após o ápice do uso de instrumentos de política agrícola, como o crédito rural subsidiado, as aquisições e controle de estoques de gêneros agropecuários por parte do governo federal e a criação de agências de pesquisa, desenvolvimento, assistência técnica e extensão rural como a Embrapa (Bacha 2004, Kageyama 1990). O auge do processo de modernização se deu entre 1960 e 1970 e gerou uma nova dinâmica econômica e produtiva, estabelecendo um perfil idealizado a ser alcançado pelos produtores rurais (Almeida 1997, Bacha 2004, Balsan 2006).

Todavia, o pacote de políticas de modernização não se adequava às especificidades de grande parte dos produtores e todo esse esforço governamental teve como resultantes, por um lado, o paulatino aumento da produtividade e a maior inserção internacional de algumas cadeias produtivas e, por outro, o atraso tecnológico de produtores que não conseguiu se adequar ao perfil idealizado pelas políticas públicas.

Passada a fase áurea de política agrícola dos anos 1960 e 1970, orientada pelo crédito de custeio e investimento fartos, garantia de preços mínimos e fortes estímulos à adoção de práticas e insumos modernos no meio rural, a década de 1980 foi marcada pela crise do endividamento estatal e crise inflacionária. A década de 1990, por sua vez, foi caracterizada pela abertura econômica, estabilização macroeconômica e mudança no modelo de incentivos (Helfand \& Rezende 2001).

Após a abertura econômica, a classe de produtores que teve as condições e realizou as ações necessárias para se tornar moderna e competitiva, consolidouse na agricultura brasileira. Os demais, que não se adequaram ao modelo, foram assolados pela competição interna e externa e pelo fim de políticas de incentivos e proteção à produção (Helfand \& Rezende 2001).

Trabalhos como os de Hoffmann \& Kassouf $(1989 a, b)$, Hoffmann \& Kageyama (1985), Hoffmann (1992), Souza \& Lima (2003) analisaram os drivers da modernização agropecuária à época, sistematizando esse processo, definindo seus aspectos mais relevantes e classificando as unidades da federação e/ou microrregiões em cada um dos aspectos identificados. A comparação macrorregional realizada aponta para a região Centro-Sul como a principal beneficiária das políticas de modernização adotadas pelo governo brasileiro e, como consequência, região mais produtiva da agropecuária no Brasil.

Nas regiões onde a modernização se intensificou houve redução de pobreza, embora o próprio processo de modernização esteja relacionado positivamente com o aumento da desigualdade de renda no meio rural (Hoffmann \& Kageyama 1985). Esses trabalhos, no entanto, não permitem a análise das características e disparidades intrarregionais devido à desagregação de dados utilizada.

Posteriormente, vários autores realizaram análises semelhantes sob um recorte regional mais restrito, porém com uma desagregação de dados ao nível de municípios. Embora não realizem a comparação entre as unidades da federação ou regiões administrativas, os autores apontam para a presença de heterogeneidade intrarregional em cada recorte espacial analisado e para as adversidades enfrentadas pelos produtores, mesmo em regiões consideradas modernas. 
Souza \& Khan (2001) corroboram essa argumentação para o estado do Maranhão, enquanto Llanilo et al. (2006) apontam que, mesmo no caso do Paraná, apontado como beneficiário das políticas de modernização, a heterogeneidade produtiva é ainda expressiva. Ferreira et al. (2004) estabeleceram 10 clusters de microrregiões distintas em termos de modernização no estado de Minas Gerais, demonstrando a ampla heterogeneidade existente dentro do estado, o que é corroborado por Cruz et al. (2006). Destacam essa heterogeneidade também Paz et al. (2006) para o estado do Rio Grande do Sul.

Se, por um lado, a análise macrorregional da modernização agropecuária oculta uma parcela de seus efeitos dentro das unidades regionais, por outro, um recorte regional restrito e com desagregação municipal dificulta a comparação com o restante do território brasileiro.

Nesse sentido, o presente trabalho teve o objetivo de identificar grupos homogêneos de municípios através de uma análise de clusters, considerando um conjunto de 30 variáveis referentes a 4.535 municípios $^{1}$ (81\% do total brasileiro), assumidas como indicadores relevantes da modernização agropecuária brasileira presentes no Censo Agropecuário de 2006, fornecendo um mapeamento detalhado dos grupos com distintos graus de modernização na agropecuária e servindo de suporte/diagnóstico para a formulação de políticas que visem o desenvolvimento socioeconômico dos produtores mais vulneráveis e a redução da heterogeneidade produtiva e econômica no meio rural brasileiro.

\subsection{O processo e as políticas de modernização}

No século XIX e início do século XX, a agricultura brasileira se caracterizava pela produção de poucos produtos destinados à exportação, organizados em torno do "Complexo Rural", em que todos os bens intermediários e meios de produção eram provenientes do próprio setor agrícola (Silva 1996). Esse setor era, portanto, autônomo e orientado pelos preços internacionais dos gêneros agrícolas exportados. Com preços favoráveis, os recursos (homens, animais de trabalho, terras etc.) eram direcionados para a produção de exportação; com preços desfavoráveis esses recursos eram realocados para atividades que garantiam a subsistência da força de trabalho e a reprodução das condições materiais da unidade produtiva (Kageyama 1990). Em suma, toda a dinâmica era centrada no meio rural, seja para exportação, seja para subsistência.

A agropecuária representava o setor dinâmico da economia brasileira e teve, até a década de 1950, uma trajetória de desenvolvimento baseada na utilização extensiva de terra e mão de obra e de técnicas tradicionais no processo produtivo (Franco e Pereira, 2008), com exceção de alguns gêneros. As tecnologias mais sofisticadas eram restritas, por exemplo, a casos como o do café para exportação (Silva \& Botelho 2014).

O processo de modernização da agropecuária brasileira que se iniciou em meados do século XX possibilitou o aumento expressivo da produtividade ${ }^{2}$, da produção de alimentos e demais gêneros agrícolas, e foi responsável por

\footnotetext{
${ }^{1}$ Parte dos municípios não apresentava dados disponíveis para uma ou mais variáveis e, portanto, foi excluída da amostra, chegando-se a uma parcela de $81 \%$ do total de municípios. Vale destacar que parte expressiva desses dados faltantes se referem a municípios nos quais a agropecuária tem participação reduzida, como pequenos municípios praianos, ilhas e municípios muito urbanizados. Ainda assim, fica reconhecida esta limitação de dados.

${ }^{2}$ De acordo com Gasques (2010), o aumento da Produtividade total dos Fatores entre 1970 e 2006 foi da ordem de $124 \%$.
} 
tornar o Brasil um dos principais players no agronegócio mundial e por contribuir significativamente para a balança comercial.

Por outro lado, mudou a dinâmica centrada no Complexo Rural, induzindo os produtores brasileiros a adotarem um pacote tecnológico específico, baseado no uso de fertilizantes e defensivos químicos e na mecanização das atividades produtivas. Nascia o Complexo Agroindustrial.

Esse processo foi coordenado pelo Estado via agencias de planejamento, bancos oficiais e institutos de pesquisa. Foram décadas de coordenação das ações por meio de políticas e subsídios regionais e setoriais, políticas de garantia de preço e de pesquisa e extensão agropecuária.

Uma vez internalizado o $D_{1}$ industrial (indústria pesada), iniciou-se, a partir de 1950, um processo de internalização do $D_{1}$ agrícola, que se intensificou nos anos 1960, com a atração e instalação de fábricas de tratores e implementos, filiais de multinacionais e fábricas de fertilizantes e defensivos, com uma participação expressiva do Estado brasileiro (Bacha 2004).

Intensificou-se, então, o processo de modernização, pautado na atuação do Estado e com o objetivo de conectar os diversos setores da economia (primário, secundário e terciário) e facilitar a acumulação de capital (Silva \& Botelho 2014). Buainain (1999) aponta que os aspectos que deram origem a essa "intervenção planejada" vinham configurando-se desde a década de 1950, a partir da criação do BNDES, da atuação do Grupo de Trabalho para o Desenvolvimento do Nordeste (posterior SUDENE) e do aparato institucional utilizado para viabilizar o Plano de Metas.

Os objetivos de tal intervenção eram bastante claros: "promover a expansão da oferta agropecuária, a expansão e diversificação das exportações e assegurar a normalidade do abastecimento doméstico" [...] que seriam alcançados "através da modernização da base técnica, fortalecimento da agroindústria e incorporação de novas terras" (Buainain 1999, p. 120-121). De acordo com Almeida (1997), a modernização da agricultura esteve ancorada em quatro noções básicas: crescimento/desenvolvimento econômico e político; abertura técnica, econômica e cultural; especialização e dependência da produção a montante, a jusante e com a sociedade global; e o surgimento de um perfil de agricultor individualista e competitivo.

Isso resultou, anos depois, na criação do Sistema Nacional de Crédito Rural (SNCR), em 1965, que, dentre outras medidas, estabeleceu o direcionamento de $10 \%$ de todos os depósitos à vista dos bancos comerciais para o financiamento agrícola, além de fontes secundárias do Tesouro Nacional que se estabeleciam conforme as demandas. Esse direcionamento teve forte efeito na expansão de crédito rural até o final da década de 1970 - crescimento real de 329\% entre 1970 e 1979 (Kageyama 1990) - período no qual essa foi a principal política agrícola de modernização. De acordo com Martine \& Garcia (1987, p. 22), o "principal instrumento que viabilizou o novo modelo agrícola, calcado na tecnificação e utilização maciça de insumos industriais [...] foi o crédito rural".

De acordo com Kageyama (1990), o crédito subsidiado (com taxas de juros sempre abaixo da taxa de inflação) foi o instrumento utilizado pelo Estado para intervir na alocação de fatores sob a lógica das estratégias de modernização. A concessão de crédito era condicionada ao uso ou aquisição dos chamados insumos modernos - sementes selecionadas, insumos químicos, planos de correção do solo e investimentos em maquinário. 
As linhas de crédito para investimento (máquinas e mudança da base técnica) e custeio (consumo corrente de sementes selecionadas, fertilizantes e outros insumos) tiveram participação majoritária na composição do crédito. O crédito para comercialização, por sua vez, era concedido via Empréstimos do Governo Federal (EGF) e teve menor participação (25\% do crédito rural), com o objetivo de formar/transformar as cooperativas e indústrias (Kageyama 1990) e de financiar a estocagem dos produtos em épocas em que os preços de mercado ficam abaixo de um mínimo estabelecido.

De acordo com Bacha (2004, p. 65) "Durante as décadas de 70 e 80, o crédito rural beneficiou, principalmente, as culturas de exportação, as regiões Sul e Sudeste e os médios e grandes produtores rurais". Isso ocorreu porque esses produtores apresentavam o perfil adequado ao plano macroeconômico do Governo Federal de incentivo às exportações: os produtos integrados ao mercado internacional (soja, milho, café, cana-de-açúcar, trigo e arroz) eram cultivados no Centro-Sul brasileiro por médios e grandes produtores, que possuíam maior capacidade administrativa e facilidade na tomada de empréstimos (Bacha 2004), devido às garantias concretas que poderiam oferecer como contrapartida.

O processo de modernização, portanto, se deu de forma diferenciada, tanto entre as diversas regiões brasileiras, quanto com relação aos produtos "escolhidos" para receber maior apoio estatal, beneficiando alguns grupos de produtores. Segundo Silva et al. (1983), o padrão tecnológico não foi totalmente absorvido pelos pequenos produtores nem mesmo planejado para eles, devido às escalas mínimas de produção requeridas, à insuficiência de recursos próprios (produtivos e financeiros) e à dificuldade de acesso por parte desses produtores às principais e mais atrativas fontes de financiamento.

A crise econômica da década de 1980 e início dos anos 1990 intensificou as disparidades entre os produtores modernos e aqueles que não acompanharam a dinâmica da modernização, além de restringir a atuação do Estado, agora preocupado com o ambiente hiperinflacionário e com as graves crises econômicas que enfrentava, reestruturando ou mesmo restringindo grande parte das políticas voltadas à modernização agropecuária.

Em meados de 1990, o governo passou a reorientar algumas das políticas no sentido de minimizar falhas de mercado e alguns dos próprios efeitos colaterais das políticas prévias de modernização, como a elevada concentração de terras, de renda e a heterogeneidade produtiva no campo. A partir de 1994, o governo distribuiu 8,7 milhões de hectares para 370 mil famílias, valor superior à toda a terra distribuída entre 1964 e 1994 (Helfand \& Rezende 2001).

Foi criado também o Programa Nacional de Fortalecimento da Agricultura Familiar (Pronaf), maior programa de financiamento da agricultura familiar no Brasil, visando prover os recursos financeiros para o desenvolvimento dessa grande parcela de produtores (84,4\% em 2006 (IBGE - Instituto Brasileiro de Geografia e Estatística 2009)) que, a princípio, estariam desfavorecidos perante aos demais. De acordo com Wedekin (2005), entre as safras 2002/03 e 2004/05, as operações do Pronaf cresceram de 926 mil para 1,62 milhões, enquanto o montante de recursos passou de $\mathrm{R} \$ 2,2$ bilhões para $\mathrm{R} \$$ 6,2 bilhões.

O marco da retomada das políticas de crédito aos produtores rurais foi, no entanto, a maior participação do Banco Nacional de Desenvolvimento Econômico e Social (BNDES) no financiamento rural, apoiado nos recursos do Fundo de Amparo ao Trabalhador (FAT). De acordo com Wedekin (2005), o financia- 
mento via MAPA-BNDES passou de R 342 milhões na safra 1999/00 para R\$ 5,2 bilhões na safra 2004/05 e, somando-se os demais recursos, o crédito para investimento na agropecuária atingiu os $\mathrm{R} \$ 8,0$ bilhões na safra 2004/05.

De acordo com Delgado (2012), os anos 2000 foram marcados por um projeto centrado na agropecuária, mesmo quando comparado ao período de industrialização da agricultura da época dos militares, no qual a modernização da agropecuária era elemento complementar à industrialização do país. A argumentação destaca, por exemplo, a presença de uma bancada ruralista ativa (Frente Parlamentar da Agropecuária), a promoção do agronegócio para as massas via mídias, o fortalecimento do SNCR através de ações centralizadoras de capital às cadeias do agronegócio via BNDES e a passividade de instituições como o INCRA, IBAMA e FUNAI (Delgado 2012).

Dessa forma, a política agrícola implementada nos anos 2000, teve, por um lado, frentes voltadas à redução de disparidades, mas, por outro, manteve esforços no sentido de estimular e dar suporte aos produtores modernos e mais integrados aos mercados mais dinâmicos no mercado nacional e internacional.

Em suma, a modernização da agropecuária nacional levou à adoção de um pacote tecnológico e ao estabelecimento de uma dinâmica específica da agropecuária nacional. A expansão regional para o Centro-Oeste se alicerçou nessa dinâmica. O processo resultou na coexistência de distintos graus de modernização na agropecuária brasileira: uma parcela de produtores moderna, produtivista e integrada aos mercados dinâmicos de exportação; outra, marcada pela pobreza relativa, produção para subsistência e arcaísmo produtivo (Martine 1991); e classes intermediárias, com características associadas ao tipo de produção predominante.

Contudo, é necessário entender como a agricultura moderna se difundiu pelo Brasil, permitindo um melhor entendimento dos resultados das políticas agrícolas e a revisão dos mecanismos. A relevância da temática se justifica pelos efeitos ambíguos atribuídos pela literatura ao processo de modernização (Gonzalez \& Costa 1998, Martine 1991, Kageyama 1986, Balsan 2006, Buainain 1999, Hoffmann \& Kageyama 1985, Silva 1996, Rezende 2006).

\section{Material e métodos: Análise de Clusters}

A análise de clusters é de um dos principais métodos de identificação de padrões entre indivíduos existentes em bases de dados multidimensionais e é utilizada em diversos campos, como a psicometria, economia, genética e medicina (Kaufman \& Rousseeuw 1990, Kassambara 2017). Os clusters são construídos de forma que cada indivíduo pertença a um e somente um subconjunto (ou assuma maior probabilidade de pertencer a um dos grupos) e que seja semelhante aos indivíduos de seu subconjunto e diferente dos indivíduos dos demais subconjuntos (Duran \& Odell 1974).

A construção de clusters requer, normalmente, algoritmos de agrupamento, métodos de ligação (linkage) e métricas de dissimilaridade (distância). Entre os métodos de agrupamento, destacam-se os hierárquicos, os métodos de partição ( $k$-means e $k$-medoids), os based-model-clustering e os density-basedclustering (Kaufman \& Rousseeuw 1990, Kassambara 2017). Dentre os métodos de ligação, destacam-se a ligação simples, ligação completa, ligação média, centroide e o método de Ward (Johnson \& Wichern 2007, Hair et al. 2009). Já 
as métricas de dissimilaridade usuais são a distância euclidiana, o Método Manhattan e a distância de Minkowski (Johnson \& Wichern 2007).

Os algoritmos de partição e hierárquicos são totalmente heurísticos, embora baseados em procedimentos intuitivamente razoáveis (Fraley \& Raftery 2002), isto é, realizam a identificação de padrões em três etapas: 1) Busca - as decisões são tomadas para atender a um determinado critério; 2) Critério de parada - restrição/critério que cessa a busca; 3) Decisão - realizada a busca e atendido o critério de parada, um conjunto de alternativas/soluções é estabelecido para a tomada de decisão. Embora pesquisas nessa temática tenham se desenvolvido, existem poucos guias sistemáticos de resolução de problemas básicos como a definição do número adequado de clusters, escolha do método de ligação e o tratamento dos outliers (Fraley \& Raftery 2002). Além disso, as propriedades estatísticas desses métodos são, geralmente, desconhecidas, impedindo a realização de inferências formais.

\subsection{Model-based Clusters}

Os model-based-clusters representam uma abordagem mais flexível, que considera a construção dos clusters com base em modelos probabilísticos formais (Bock 1996). Diferentemente dos métodos heurísticos citados, assumem que os dados são oriundos de uma distribuição mista de probabilidades, composta de um número finito de clusters. Muitos modelos heurísticos, como o $k$-means, são aproximações de casos particulares desse tipo de modelagem, classificada como uma metodologia do tipo "unsupervised machine learning" (Kassambara 2017, Kaufman \& Rousseeuw 1990).

O problema de definição do número adequado de clusters e do método apropriado de ligação é reformulado como um problema de escolha do modelo estatístico. Além disso, distintos modelos em termos de número de componentes da distribuição de probabilidade podem ser comparados objetivamente (Fraley \& Raftery 2002). A estratégia é construída pela aplicação de dois métodos complementares: a aglomeração hierárquica baseada na classificação de probabilidade (Murtagh \& Raftery 1984, Banfield \& Raftery 1992) e o algoritmo "Expectation Maximization" (EM) (Mclachlan \& Basford 1988, Celeux \& Govaert 1992), que se trata de uma abordagem generalizada para a estimação por máxima verossimilhança que considera dados/informações não observáveis ${ }^{3}$ (Do \& Serafim 2008).

O algoritmo EM computa as respectivas distribuições de probabilidade ("E-step") a partir de parâmetros prévios a respeito de cada cluster e, então, reestima os parâmetros por métodos de otimização com base nos parâmetros correntes ("M-step"). O processo se repete até a convergência dos parâmetros. Conforme Melnykov \& Maitra (2010), considerando o E-step na iteração s, a probabilidade de um indivíduo $i$ ser um elemento do cluster $k$ é dada pela equação (1):

$$
\pi_{i k}^{s}=\operatorname{Prob}\left\{X_{i} \in k-\text { th Cluster } \mid X_{i}, \vartheta^{(s-1)}\right\}=\frac{\pi_{k}^{(s-1)} f_{k}\left(x_{i}, \vartheta_{k}^{s-1}\right)}{\sum_{k^{\prime}=1}^{K} \pi_{k^{\prime}}^{(s-1)} f_{k}\left(x_{i}, \vartheta_{k^{\prime}}^{s-1}\right)}
$$

\footnotetext{
${ }^{3} \mathrm{Na}$ análise de clusters, as informações dadas são as características dos indivíduos, determinadas por $\mathrm{p}$ variáveis observáveis. As informações não observáveis se referem a qual cluster cada indivíduo assume maior probabilidade de pertencimento e o número e modelo ótimo de clusters.
} 
em que $\pi_{i k}^{s}$ é a probabilidade de o indivíduo $i$ ser um elemento do cluster $k$, $X_{i}$ é o vetor de características do indivíduo $i$ e $\vartheta^{s-1}$ é o vetor de parâmetros estimados na iteração anterior $(s-1)$. Por sua vez, o M-step maximiza a probabilidade condicional esperada, denotada como Função-Q, com respeito ao vetor de parâmetros $\vartheta$. Quando da convergência dos passos do EM, obtém-se o vetor estimado de parâmetros para os dados originais observados. No caso da distribuição Gaussiana multivariada mista, a função densidade de probabilidade correspondente é dada pela equação (2) e a Função Q correspondente é dada pela equação (3):

$$
\begin{gathered}
f(x, \vartheta)=\sum_{k}^{K} \pi_{k} \phi\left(x, \mu_{k}, \sum_{k}\right) \\
=\sum_{k}^{K} \pi_{k}\left\{(2 \pi)^{-\frac{p}{2}}\left|\sum_{k}\right|^{-\frac{1}{2}} \exp \left[-\frac{1}{2}\left(x-\mu_{k}\right)^{\prime} \sum_{k}^{-1}\left(x-\mu_{k}\right)\right]\right\} \\
Q\left(\vartheta, x_{1}, x_{2}, \ldots, x_{n}\right)=-\frac{1}{2} \sum_{i=1}^{n} \sum_{k=1}^{K} \pi_{i k}\left\{\log \mid \sum_{k} \|+\left(x-\mu_{k}\right)^{\prime} \sum_{k}^{-1}\left(x-\mu_{k}\right)\right\} \\
+\sum_{i=1}^{n} \sum_{k=1}^{K} \pi_{i k} \log \pi_{k}-\frac{p n}{2} \log 2 \pi
\end{gathered}
$$

Os parâmetros a priori (centros e covariâncias dos clusters) são obtidos por meio de um modelo de cluster hierárquico, a partir dos quais o algoritmo EM vai realizar as iterações e obter as estimativas finais do vetor de parâmetros. Como resultado, a cada indivíduo será associada uma probabilidade de pertencer a cada um dos clusters. As características geométricas (volume, formato e orientação) de cada cluster são definidas pela matriz de covariâncias dos dados, que é parametrizada de diversas formas para avaliar qual dos modelos de cluster apresenta o melhor ajuste (Fraley \& Raftery 2002). As matrizes de covariância $\sum_{k}$ são decompostas conforme a equação (4) (Fraley \& Raftery 2002):

$$
\sum_{k}=\lambda_{k} D_{k} A_{k} D_{k}^{T}
$$

em que $\boldsymbol{D}_{k}$ é uma matriz ortogonal de autovetores e determina a orientação do $k$-ésimo cluster, $\boldsymbol{A}_{k}$ é uma matriz diagonal de elementos proporcionais aos autovalores que determina o formato do $k$-ésimo cluster e $\lambda_{k}$ é uma constante de proporcionalidade que determina o volume do $k$-ésimo cluster.

São considerados e comparados 14 tipos distintos de modelos, identificados por três letras, em uma amplitude predefinida e finita de número de clusters (de 1 a 100 neste trabalho, totalizando 1.400 modelos comparados), conforme segue: EII; VII; EEI; VEI; EVI; VVI; EEE; EVE; VEE; VVE; EEV; VEV; EVV; e VVV. O primeiro identificador se refere ao volume, o segundo ao formato e o terceiro à orientação do cluster. A letra E representa igualdade "Equals" no respectivo atributo do cluster; a letra V representa que o respectivo atributo varia entre os clusters "Variable"; e a letra I representa que os clusters possuem uma orientação coordenada aos eixos "coordinate axes". 
A escolha do número ótimo de clusters tem como base o fator de Bayes (Fraley \& Raftery 2002, Kassambara 2017). Se vários modelos, $M_{1}, M_{2}, \ldots, M_{k}$ são considerados, com probabilidades a priori $p(M k), k=1,2, \ldots, K$, então, pelo teorema de Bayes, a probabilidade a posteriori de Mk dado o conjunto de dados $D$ é proporcional à probabilidade de $D$, dado o modelo $M_{k}$, multiplicada pela probabilidade a priori de $M_{k}$, conforme a equação (5):

$$
p\left(M_{k} \mid D\right) \propto p\left(D \mid M_{k}\right) p\left(M_{k}\right)
$$

Quando existem parâmetros desconhecidos, pela Lei da Probabilidade Total, $p\left(D \mid M_{k}\right)$ é obtida integrando os parâmetros, conforme a equação (6):

$$
p\left(D \mid M_{k}\right)=\int p\left(D \mid \vartheta_{k}, M_{k}\right) p\left(\vartheta_{k} \mid M_{k}\right) d \vartheta_{k}
$$

em que $p\left(\vartheta_{k} \vee M_{k}\right)$ é a distribuição a priori de $\vartheta_{k}$, o vetor de parâmetros do modelo $M_{k}$. A abordagem Bayesiana consiste, então, em escolher o modelo com maior probabilidade a posteriori (dado o conjunto de dados, escolher o modelo mais provável). O Fator de Bayes comparando dois modelos, $M_{1}$ e $M_{2}$, é definido como a razão expressa na equação (7):

$$
B_{12}=\frac{p\left(D \mid M_{1}\right)}{p\left(D \mid M_{2}\right)}
$$

O modelo $M_{1}$ será escolhido se $B_{12}>1$, e quanto maior o fator $B_{12}$, maiores as evidências em favor de $M_{1}$. A verossimilhança integrada "integrated likelihood” pode ser aproximada pelo Critério Bayesiano de Informação (BIC) Fraley \& Raftery (2002), conforme a equação (8):

$$
2 \log p\left(D \mid M_{k}\right) \approx 2 \log p\left(D \mid \hat{\vartheta}, M_{k}\right)-v_{k} \log n=B I C_{k}
$$

em que $v_{k}$ é o número de parâmetros independentes a serem estimados no modelo Mk. Assim, é escolhido o modelo que apresente o maior valor do Critério de Informação Bayesiano, ao contrário da interpretação comumente realizada em análises de regressão. Justamente pela flexibilidade dessa abordagem e pela conhecida heterogeneidade presente na agropecuária brasileira, este trabalho adotou como método o Model-Based-Clusters.

\subsection{Variáveis utilizadas}

As variáveis elencam os chamados "insumos modernos" utilizados na agropecuária e são baseadas nos trabalhos de Hoffmann \& Kassouf $(1989 a, b)$, Souza \& Lima (2003) e Campos et al. (2014). Algumas variáveis desses quatro trabalhos foram substituídas por variáveis condizentes presentes no Censo Agropecuário de 2006.

Diversas variáveis são compostas por razões, nas quais os denominadores são: o total de estabelecimentos agropecuários do município (TE); a área total de pastagem (AP); a área aproveitável para práticas agropecuárias (AA); área de lavoura permanente e temporária $(\mathrm{AL})$ e o pessoal ocupado nos estabelecimentos expresso em Equivalente-Homem-Ano (EHA). 
A medida de mão de obra nos estabelecimentos rurais - equação (9) - foi obtida através de uma ponderação de duas metodologias. A primeira delas é a de equivalente-homem, utilizada por Hoffmann \& Kassouf $(1989 a, b)$ e proposta por Silva \& Kageyama (1983), visando equalizar a força de trabalho de homens, mulheres e crianças no campo. A segunda foi proposta por Kageyama et al. (2014), visando estabelecer a mão de obra empregada nos estabelecimentos rurais ao longo de todo o ano, uma vez que a informação sobre pessoal ocupado nos estabelecimentos disponível no Censo Agropecuário de 2006 diz respeito ao dia 31/12/2006.

$$
\begin{aligned}
E H A_{i} & =\sum_{i=1}^{n}\left(H_{i}+0,8 \cdot M_{i}+0,6 \cdot C_{i}\right)\left(0,08 \cdot T_{(0-60) i}\right. \\
& \left.+0,33 \cdot T_{(61-180) i}+0,75 \cdot T_{(181-360) i}\right)
\end{aligned}
$$

em que: $H_{i}, M_{i}$ e $C_{i}$ são as porcentagens de homens, mulheres e crianças, respectivamente, que compõem pessoal ocupado nos estabelecimentos agropecuários do município $i ; T_{(0-60) i}, T_{(61-180) i}$ e $T_{(181-360) i}$ são as quantidades de pessoas que trabalharam de 0 a 60 dias, de 61 a 180 dias e de 181 a 360 dias, respectivamente, ao longo do ano.

O nível de escolaridade médio das pessoas que dirigem os estabelecimentos foi definido como a soma das porcentagens de dirigentes em cada grau de formação/escolaridade, ponderada por uma escala discreta de 0 a 5 , na qual 0 significa o menor nível de escolaridade e 5 o maior, e dividida pelo maior valor de ponderação, conforme equação (10):

$$
N E_{i}=\frac{0 . A_{i}+1 \cdot B_{i}+2 \cdot C_{i}+3 \cdot D_{i}+4 \cdot E_{i}+5 \cdot F_{i}}{5}
$$

em que: $A_{i}$ é a porcentagem de dirigentes que não sabe ler e escrever em um município $i ; B_{i}$ a porcentagem de dirigentes que não possuem formação, mas sabe ler e escrever; $C_{i}$ a porcentagem de dirigentes que possui ensino fundamental incompleto ou participou de programas para alfabetização de adultos; $D_{i}$ a porcentagem de dirigentes com ensino fundamental completo; $E_{i}$ a porcentagem de dirigentes com ensino médio completo (técnico ou não); $\mathrm{e}$ $F_{i}$ a porcentagem de dirigentes que possui formação superior. O índice possui o intervalo [0;1]; o limite inferior é obtido quando a totalidade dos dirigentes de um município não sabe ler e escrever e o limite superior é obtido quando essa totalidade possui formação superior.

O índice de orientação técnica recebida pelos dirigentes dos estabelecimentos foi definido como a soma das porcentagens de dirigentes em cada classe de orientação, ponderada por uma escala discreta de 0 a 2, na qual 0 representa a inexistência de orientação técnica e 2 a orientação técnica regular, dividida pelo maior fator de ponderação conforme equação (11):

$$
O T_{i}=\frac{0 . N R_{i}+1 \cdot R O_{i}+2 \cdot R R_{i}}{2}
$$

em que: $N R_{i}$ é a porcentagem de dirigentes que não recebeu orientação técnica; $R O_{i}$ é a porcentagem de dirigentes que recebeu orientação técnica ocasionalmente; e $R R_{i}$ é a porcentagem de dirigentes que recebeu orientação técnica 
regularmente. A interpretação e intervalo são análogos ao caso do indicador de escolaridade.

O índice de adoção de suplementação animal foi definido conforme a equação (12):

$$
S_{i}=\frac{0 . N U_{i}+1 . U S_{i}+2 . U R_{i}}{2}
$$

em que: $N U_{i}$ é a porcentagem de estabelecimentos que não utiliza suplementação animal no município $i$; $U S_{i}$ é a porcentagem que utiliza sal como suplementação animal; e $U R_{i}$ é a porcentagem que utiliza ração, grãos e subprodutos agroindustriais como suplementação animal. A interpretação e intervalo são análogos ao caso do indicador de escolaridade.

O índice de integração com o mercado foi definido conforme a equação (13):

$$
I I_{i}=\frac{0 . N I_{i}+1 . P I_{i}+2 . I_{i}+3 . M I_{i}}{3}
$$

em que: $N I_{i}$ é a porcentagem de estabelecimentos que não declararam o grau de integração com o mercado; $P I_{i}$ é a porcentagem de estabelecimentos pouco integrados; $I_{i}$ é a porcentagem de estabelecimentos integrados; e $M I_{i}$ é a porcentagem de estabelecimentos muito integrados. A interpretação e intervalo são análogos ao caso do indicador de escolaridade.

Foram obtidos dados de 4.535 municípios brasileiros no Censo Agropecuário de 2006 (IBGE - Instituto Brasileiro de Geografia e Estatística 2009). A Tabela 1 apresenta as médias regionais das variáveis selecionadas.

A região Sul apresentou o maior percentual de estabelecimentos que utilizaram força mecânica $(\mathrm{X} 1=57 \%)$, seguida pela região Sudeste $(41 \%)$, CentroOeste $(38 \%)$, Nordeste $(23 \%)$ e Norte $(17 \%)$. O Centro-Sul ficou à frente também no número de tratores por EHA (X5), no número de máquinas e implementos agrícolas por EHA (X6) e no valor dos tratores, máquinas, veículos e implementos por área de lavoura (X12). Já no valor dos tratores, máquinas, veículos e implementos por EHA as regiões Centro-Oeste e Norte ficaram à frente do Sul e Sudeste, devido ao uso reduzido de mão de obra na produção agropecuária e ao grande porte das máquinas utilizadas no Norte e CentroOeste.

As variáveis relacionadas à integração dos estabelecimentos ao mercado demonstram o protagonismo da região Sul, sobretudo no que diz respeito ao percentual de estabelecimentos que obtiveram financiamentos no ano de referência (X7), na qual a região Sul apresentou percentual de $36 \%$ enquanto todas as demais não ultrapassaram os $15 \%$. A região Sul apresentou também elevado percentual de estabelecimentos associados à cooperativas e/ou entidades de classe $(\mathrm{X} 29=56 \%)$, enquanto as demais regiões se situaram entre $30 \%$ e 37\%. Com relação ao índice de integração ao mercado (X30), o conjunto Centro-Oeste, Sul e Sudeste apresentou os maiores valores e o Nordeste permaneceu em último lugar.

A respeito das variáveis de melhoramento do solo e das condições produtivas, as regiões Centro-Oeste e Norte apresentaram os maiores valores da variável X2 - percentuais de área de pastagem que é plantada (81\% e 76\%, 
Tabela 1: Médias regionais das variáveis selecionadas

\begin{tabular}{|c|c|c|c|c|c|c|}
\hline Variáveis & NO & NE & SE & $\mathbf{S}$ & $\mathrm{CO}$ & BR \\
\hline X1 - Est. que utilizaram força de trabalho mecânica/TE; & 0,17 & 0,23 & 0,41 & 0,57 & 0,38 & 0,37 \\
\hline X2 - Área de pastagem plantada/AP; & 0,76 & 0,39 & 0,55 & 0,38 & 0,81 & 0,50 \\
\hline X3 - Área trabalhada/AA; & 0,46 & 0,41 & 0,53 & 0,53 & 0,61 & 0,50 \\
\hline X4 - Área com lavouras permanentes e temporárias/AA; & 0,08 & 0,22 & 0,24 & 0,42 & 0,12 & 0,26 \\
\hline X5 - Número de tratores/EHA; (Un/EHA) & 0,05 & 0,02 & 0,15 & 0,20 & 0,19 & 0,12 \\
\hline X6 - Número de máquinas e impl. agrícolas/EHA; (Un/EHA) & 0,16 & 0,20 & 0,64 & 1,13 & 0,61 & 0,59 \\
\hline X7 - Est. com financiamentos no ano de referência/TE; & 0,11 & 0,14 & 0,15 & 0,36 & 0,15 & 0,19 \\
\hline X8 - Est. que realizaram despesas com combustíveis/TE; & 0,61 & 0,43 & 0,44 & 0,62 & 0,57 & 0,51 \\
\hline X9 - Est. que utilizaram técnicas de plantio em nível/TE; & 0,15 & 0,25 & 0,39 & 0,42 & 0,18 & 0,32 \\
\hline X10 - Est. que utilizaram técnicas de plantio direto/TE; & 0,05 & 0,04 & 0,04 & 0,38 & 0,07 & 0,13 \\
\hline X11 - Est. que utilizaram técnicas de rotação de cultura/TE; & 0,05 & 0,08 & 0,09 & 0,32 & 0,06 & 0,14 \\
\hline $\mathrm{X} 12$ - Valor dos bens móveis/AL; (R \$ mil/ha) & 0,55 & 0,49 & 1,14 & 1,81 & 0,74 & 1,03 \\
\hline X13 - Valor dos bens móveis/EHA; (R \$ mil/EHA) & 31,13 & 6,78 & 24,45 & 27,56 & 74,02 & 24,98 \\
\hline X14 - Est. com despesas com sal e ração para animais/TE; & 0,46 & 0,26 & 0,48 & 0,50 & 0,65 & 0,43 \\
\hline X15 - PIB da agricultura/AA; (R\$ mil/ha) & 0,28 & 0,50 & 0,87 & 1,05 & 0,22 & 0,70 \\
\hline X16 - PIB da agricultura/EHA; (R\$ mil/EHA) & 14,30 & 5,96 & 19,25 & 16,91 & 24,34 & 14,88 \\
\hline X17 - Est. com despesas com adubos/TE; & 0,14 & 0,14 & 0,45 & 0,66 & 0,23 & 0,37 \\
\hline X18 - Est. com despesas com corretivos do solo/TE; & 0,04 & 0,03 & 0,23 & 0,15 & 0,10 & 0,13 \\
\hline X19 - Est. com despesas com sementes e mudas/TE; & 0,08 & 0,06 & 0,15 & 0,38 & 0,13 & 0,17 \\
\hline X20 - Est. com despesas com agrotóxicos/TE; & 0,15 & 0,22 & 0,26 & 0,61 & 0,17 & 0,31 \\
\hline X21 - Est. com despesas com compra de animais/TE; & 0,18 & 0,21 & 0,20 & 0,39 & 0,23 & 0,25 \\
\hline X22 - Est. com despesas com medicamentos para animais/TE; & 0,62 & 0,48 & 0,64 & 0,69 & 0,80 & 0,62 \\
\hline X23 - Est. que utilizaram energia elétrica/TE; & 0,49 & 0,64 & 0,83 & 0,85 & 0,77 & 0,75 \\
\hline X24 - Índice de escolaridade da pessoa que dirige o est.; (Índice) & 0,37 & 0,26 & 0,49 & 0,46 & 0,48 & 0,41 \\
\hline X25 - Índice de orientação técnica recebida; (Índice) & 0,14 & 0,08 & 0,26 & 0,38 & 0,23 & 0,22 \\
\hline X26 - Índice médio de uso de suplementação animal; (Índice) & 0,53 & 0,59 & 0,65 & 0,65 & 0,62 & 0,62 \\
\hline X27 - Est. muito especializados/TE; & 0,25 & 0,21 & 0,30 & 0,17 & 0,26 & 0,23 \\
\hline X28 - Est. especializados/TE; & 0,38 & 0,35 & 0,36 & 0,38 & 0,44 & 0,37 \\
\hline X29 - Est. associados a cooperativas ou entidades de classe/TE; & 0,35 & 0,37 & 0,35 & 0,56 & 0,30 & 0,40 \\
\hline X30 - Índice médio de integração com o mercado; (Índice) & 0,54 & 0,52 & 0,62 & 0,62 & 0,61 & 0,59 \\
\hline
\end{tabular}

Fonte: Elaborado pelo autor com base no Censo Agropecuário 2006 (IBGE, 2009). 
respectivamente). No percentual da área aproveitável que é ocupada com lavouras permanentes ou temporárias (X4), a região Sul se destacou com $42 \%$, seguida pelo Sudeste, com $24 \%$. Os maiores percentuais de estabelecimentos que realizaram despesas com adubos (X17), sementes (X19) e agrotóxicos (X20) estão associados à região Sul. Já o Sudeste apresentou o maior percentual de estabelecimentos que utilizaram corretivos para o solo (X18). Para as demais variáveis relacionadas às melhorias das condições produtivas, como a suplementação animal e as despesas com sal e ração, os valores médios apresentados pelas regiões Sul, Centro-Oeste e Sudeste são superiores aos apresentados pelo Norte e Nordeste.

Com relação às variáveis que representam "boas práticas" de produção, a região Sul se destaca, por exemplo, com altos percentuais de estabelecimentos que realizaram plantio em nível (X9), plantio direto na palha (X10) e rotação de culturas (X11). Já o grau de escolarização das pessoas que dirigem os estabelecimentos (X24) e o grau de orientação técnica recebida demonstram a situação bastante desfavorável das regiões Norte e Nordeste.

Esse descritivo de médias corrobora trabalhos como os de Hoffmann \& Kageyama (1985), Hoffmann \& Kassouf $(1989 a, b)$, Hoffmann (1992) e Souza \& Lima (2003) ao apontar essa preponderância das regiões Centro-Oeste, Sudeste e Sul no que diz respeito à modernização da agropecuária. Além disso, demonstra que esse hiato permaneceu ao longo do tempo, mesmo com mudanças intensas em termos de política agrícola entre 1950 e 2006.

\section{Resultados e discussões}

Considerando os 4.535 municípios e os 30 indicadores de modernização selecionados, foram realizados os procedimentos descritos na seção metodológica, com auxílio do software $\mathrm{R}$, tendo como destaque os seguintes pacotes: "clustertend" - avalia a adequação da base de dados à análise de clusters por meio da estatística de Hopkins (quanto mais próxima de zero, melhor a adequação) (Lawson \& Jurs 1990); "mclust" - determina dentre os 14 tipos de reparametrização da matriz de covariâncias, o melhor modelo e número ótimo de clusters de acordo com o BIC (Scrucca et al. 2016, Fraley \& Raftery 2002).

O teste de Hopkins resultou em um índice de 0,0978, valor próximo de zero e que, portanto, demonstra a adequação da base de dados à análise de clusters. Como resultante, com base no Critério de Informação Schwarz ($288.389,9$ ), o modelo com melhor ajuste é composto por 9 clusters com a configuração VEV (volume variável, forma equivalente e orientação variável com relação aos eixos).

Nesta seção, são discutidos os principais destaques dos clusters analisados, que são apresentados nas Tabelas 2, 3 e 4. Os valores médios de cada uma das 30 variáveis para os 9 clusters estão detalhados na Tabela A.1 (Apêndice), bem como as médias nacionais de cada variável e indicadores correlatos. As médias nacionais foram tomadas como valores de referência para a comparação com cada cluster. Para facilitar a visualização, foi utilizada uma escala de cores que representa o desempenho dos clusters em cada variável de análise, partindo do vermelho (pior desempenho) até o azul (melhor desempenho).

Os clusters foram plotados no mapa municipal brasileiro, fornecendo uma visão regionalizada dos indicadores de modernização. A Figura 1 ilustra os 9 clusters em conjunto, ordenados com base na mediana dos valores médios 
municipais em cada variável analisada para minimizar o efeito de valores extremos.

Figura 1: Clusters construídos com variáveis de modernização agropecuária

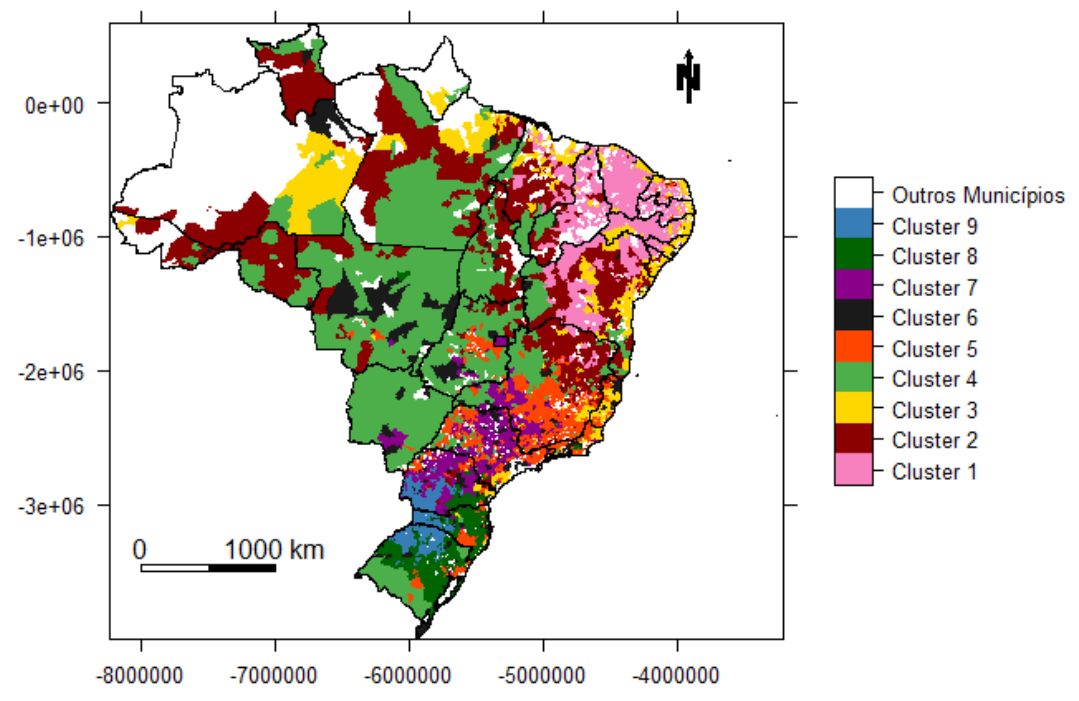

Fonte: Resultados da pesquisa.

De forma geral, foram agrupadas algumas áreas conhecidas, não apenas no meio rural, por aspectos associados à pobreza e às condições adversas de produção e sobrevivência de suas populações, como o semiárido nordestino, o norte de Minas gerais e parcelas da região Norte do país.

Os três primeiros clusters possuem o pior desempenho em termos de modernização agropecuária, com indicadores que revelam o uso extensivo do solo, baixo grau de capitalização dos produtores, baixos níveis de mecanização na produção agropecuária, bem como o percentual reduzido de produtores que fazem uso de adubos, corretivos do solo, defensivos, sementes e mudas e de técnicas como o plantio em nível, plantio direto e rotação de culturas.

O acesso ao crédito nesse conjunto de clusters é restrito quando comparado à média nacional, assim como os índices de escolaridade e de orientação técnica recebida pelos produtores. Todos esses aspectos se conformam de modo que esses três clusters apresentem baixa capacidade de geração de riqueza. A Figura 2 ilustra os três primeiros clusters isolados dos demais e em ordem crescente de modernização, tendo como critério a mediana dos valores médios encontrados para todas as variáveis padronizadas analisadas em cada cluster. A Tabela 2, por sua vez, apresenta as características comuns entre os 3 clusters com menor nível de modernização e suas características discriminantes, bem como indicadores correlatos.

O Cluster 1 é formado por 653 municípios, dos quais $96 \%$ pertence à região Nordeste, sobretudo no semiárido brasileiro e em partes do Meio Norte. Ele concentra $23 \%$ dos estabelecimentos agropecuários e $22 \%$ da mão de obra rural no país, embora represente apenas $8 \%$ da área aproveitável para atividades agropecuárias e $5 \%$ do PIB da agropecuária. Sua pauta produtiva é composta pela criação de animais de grande porte (19\%), produção de leite 
Tabela 2: Principais características comuns e específicas dos clusters 1, 2 e 3

\section{Características comuns entre os clusters}

- Baixo uso de corretivos, adubos, defensivos, sementes e mudas;

- Baixo grau de mecanização e capitalização dos estabelecimentos;

- Uso extensivo do solo, tanto na agricultura quanto na pecuária;

- Baixa adoção de técnicas como plantio direto, rotação de cultura e plantio em nível;

- Baixo índice de escolaridade e de orientação técnica;

- Acesso reduzido ao crédito;

- Baixa capacidade de geração de riqueza per capita e por hectare.

\begin{tabular}{|c|c|c|}
\hline \multicolumn{3}{|c|}{ Características específicas de cada cluster } \\
\hline Cluster 1 & Cluster 2 & Cluster 3 \\
\hline $\begin{array}{l}\text { Grau de } \text { associati- }^{-} \text {vismo e cooperati- } \\
\text { vismo acima da média } \\
\text { nacional; }\end{array}$ & $\begin{array}{l}\text { Especialização na cria- } \\
\text { ção de animais; }\end{array}$ & $\begin{array}{l}\text { Atividades demandan- } \\
\text { tes em mão de obra; }\end{array}$ \\
\hline $\begin{array}{l}\text { Adoção de suplemen- } \\
\text { tação animal; }\end{array}$ & $\begin{array}{l}\text { Elevada adoção de sal, } \\
\text { ração e medicamentos } \\
\text { para animais; }\end{array}$ & $\begin{array}{l}\text { Pequenas melhorias } \\
\text { em adoção de técnicas } \\
\text { como plantio em nível } \\
\text { e rotação de cultura; }\end{array}$ \\
\hline $\begin{array}{l}\text { Nível muito baixo de } \\
\text { mecanização; }\end{array}$ & $\begin{array}{l}\text { Elevado percentual de } \\
\text { pastagem plantada; }\end{array}$ & $\begin{array}{l}\text { Nível muito baixo de } \\
\text { mecanização; }\end{array}$ \\
\hline & $\begin{array}{l}\text { Menor nível de acesso } \\
\text { ao crédito }\end{array}$ & \\
\hline 653 municípios & 601 municípios & 582 municípios \\
\hline $\begin{array}{l}\text { Semiárido Brasileiro e } \\
\text { Meio Norte }\end{array}$ & $\begin{array}{l}\text { Meio Norte e Bahia, re- } \\
\text { gião Norte e parcela } \\
\text { norte de Minas Gerais }\end{array}$ & $\begin{array}{l}\text { Nordeste (Zona da } \\
\text { Mata) e Espírito Santo }\end{array}$ \\
\hline $\begin{array}{l}23 \% \text { dos estabeleci- } \\
\text { mentos }\end{array}$ & $\begin{array}{l}14 \% \text { dos estabeleci- } \\
\text { mentos }\end{array}$ & $\begin{array}{l}16 \% \text { dos estabeleci- } \\
\text { mentos }\end{array}$ \\
\hline $22 \%$ da mão de obra & $16 \%$ da mão de obra & $18 \%$ da mão de obra \\
\hline $\begin{array}{l}8 \% \text { da área agricultá- } \\
\text { vel }\end{array}$ & $\begin{array}{l}18 \% \text { da área agricultá- } \\
\text { vel }\end{array}$ & $\begin{array}{l}6 \% \text { da área agricultá- } \\
\text { vel }\end{array}$ \\
\hline $\begin{array}{l}5 \% \text { do PIB agropecuá- } \\
\text { rio }\end{array}$ & $\begin{array}{l}9 \% \text { do PIB agropecuá- } \\
\text { rio }\end{array}$ & $\begin{array}{l}11 \% \text { do PIB agropecuá- } \\
\text { rio }\end{array}$ \\
\hline $\begin{array}{l}\text { Animais de grande } \\
\text { porte, leite, aves, ovos, } \\
\text { banana, milho, feijão, } \\
\text { arroz e mandioca }(74 \% \\
\text { do VBP) }\end{array}$ & $\begin{array}{l}\text { Animais de grande } \\
\text { porte, leite, silvicul- } \\
\text { tura, mandioca, milho, } \\
\text { arroz, soja e banana } \\
(74 \% \text { do } \mathrm{VBP})\end{array}$ & $\begin{array}{l}\text { Banana, cana, mandi- } \\
\text { oca, café, laranja, ca- } \\
\text { cau, aves, ovos horti- } \\
\text { cultura e animais de } \\
\text { grande porte }(70 \% \text { do } \\
\text { VBP })\end{array}$ \\
\hline $\begin{array}{l}\text { Área média: } 24 \text { hecta- } \\
\text { res }\end{array}$ & $\begin{array}{l}\text { Área média: } 79 \text { hecta- } \\
\text { res }\end{array}$ & $\begin{array}{l}\text { Área média: } 22 \text { hecta- } \\
\text { res }\end{array}$ \\
\hline
\end{tabular}

Fonte: Resultados da pesquisa. 
Figura 2: Clusters menos avançados no processo de modernização

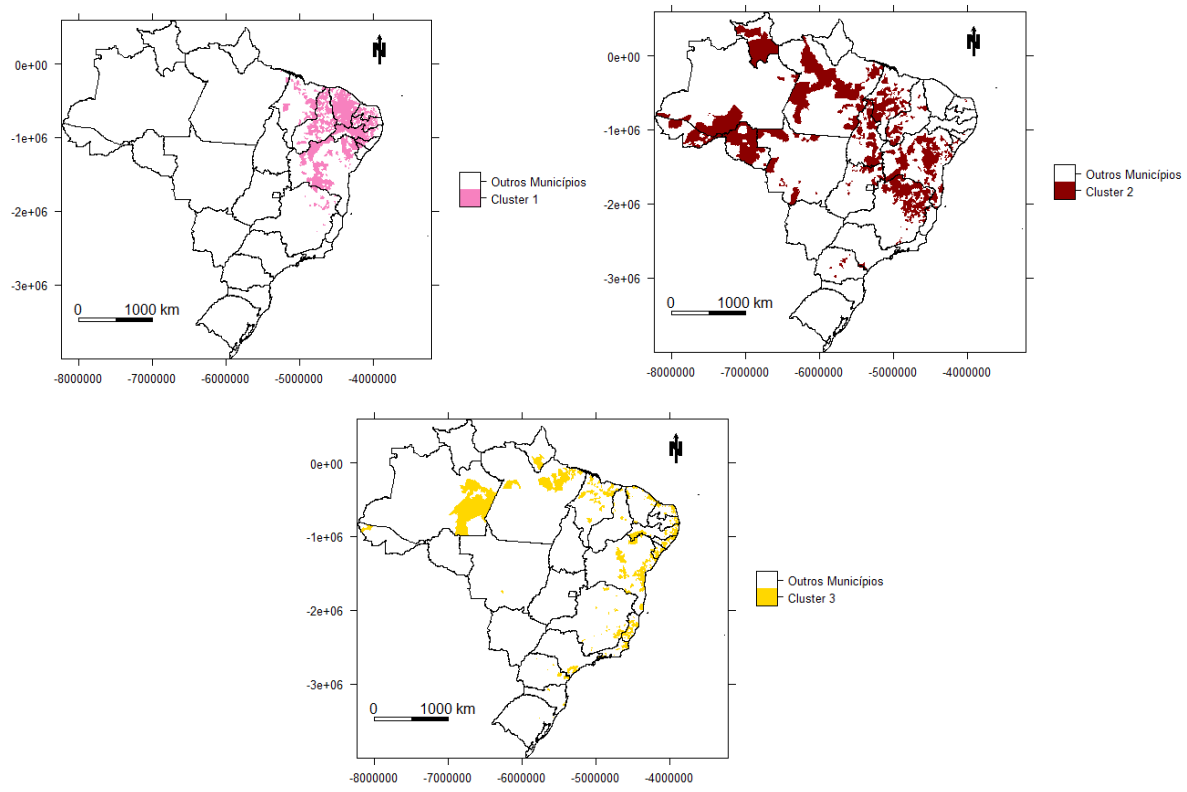

Fonte: Resultados da pesquisa.

de vaca $(9 \%)$, aves $(7 \%)$, ovos de galinha $(3 \%)$, banana $(13 \%)$, milho $(11 \%)$, feijão fradinho $(6 \%)$, arroz $(3 \%)$ e mandioca $(3 \%)$, que somam $74 \%$ do valor de produção (IBGE - Instituto Brasileiro de Geografia e Estatística 2009).

Não bastassem as mazelas do clima semiárido, o Cluster 1 é caracterizado por valores baixos em quase todas as métricas de modernização, com destaque para os baixos percentuais de estabelecimentos que realizaram despesas com corretivos, adubos, sementes e mudas, sal, ração e medicamentos para animais. Dessa forma, tanto agricultura quanto pecuária são realizadas de forma tradicional, explorando os recursos disponíveis no solo.

São baixas também as parcelas de área aproveitável que é trabalhada, de pastagem que é plantada e a parcela de área que é ocupada com lavouras permanentes e temporárias. Isso caracteriza uma agropecuária extensiva, com pouca tecnologia, muita mão de obra e baixos níveis de produtividade. Além disso, esse sistema produtivo se dá em estabelecimentos pequenos, com área de, em média, 24 hectares, o que impossibilita ganhos com produção em grande escala. Esses aspectos, caracterizados com o baixo nível de integração ao mercado desse cluster, o caracterizam, em grande medida, pela produção para subsistência.

As pequenas parcelas de área incorporadas ao processo produtivo são utilizadas por produtores com baixo nível de escolaridade e orientação técnica, o que contribui para a baixa adoção de técnicas como rotação de cultura, plantio direto e plantio em nível, que não são adotadas pela maioria dos estabelecimentos (ver Apêndice). Além disso, é baixo o grau de mecanização, uma vez que apenas $25 \%$ dos estabelecimentos, em média, utilizam força de trabalho mecânica e a relação de tratores por trabalhador é de 1 trato para cada 95 trabalhadores, enquanto a média nacional é de 1 para 8 .

Os fatores climáticos são condicionantes de todo o manejo realizado pelos 
produtores, o que requer formas de mitigação de riscos e garantia da produção, como o fornecimento de ração e suplementação animal, irrigação, cultivo de variedades mais resistentes às adversidades climáticas, plantio em nível, dentre outras práticas. No entanto, as características dos produtores são incompatíveis com esse nível tecnológico. O planejamento e suporte técnico para a seleção de culturas e animais bem adaptados às condições climáticas da região poderiam contribuir para a produção e geração de renda local.

Uma das possibilidades de difusão de conhecimento técnico, organização da produção e maior poder de barganha na compra e venda poderia se dar por meio das cooperativas. No entanto, embora o percentual de produtores associados e/ou cooperados seja relativamente alto, a maior parcela está ligada às associações de classe e não às cooperativas de produtores. Essas associações não possuem os mesmos objetivos e níveis de organização que levem aos produtores esse conhecimento técnico e permitam ganhos em termos de preços, tecnologia e orientação técnica, como ocorre, por exemplo, na região Sul do Brasil.

Dessa forma, políticas públicas que visem minimizar as precárias condições de produção e reprodução das atividades agropecuárias nesse cluster, bem como integrar esses produtores ao mercado, devem voltar-se a aspectos básicos, como orientação técnica, formação de cooperativas que propiciem melhores condições de compra e venda, difundam o conhecimento técnico e viabilizem a aquisição e uso de máquinas e equipamentos em pequenas escalas de produção. Além disso, é necessário suporte financeiro associado à adoção dessas práticas para viabilizar e desenvolver tais atividades. Pelo lado da demanda, os estímulos podem vir por meio de instrumentos como os mercados institucionais e as comunidades de suporte à agricultura, mitigando algumas das vulnerabilidades características desses produtores.

O Cluster 2 é formado por 601 municípios, 39\% deles situados na região Nordeste, sobretudo no Meio Norte e Bahia, 28\% na região Norte e $26 \%$ na região Sudeste, na parcela setentrional de Minas Gerais. Sua pauta produtiva é concentrada na criação de animais de grande porte (38\%), produção de leite de vaca $(9 \%)$, silvicultura $(7 \%)$, mandioca $(6 \%)$, milho $(4 \%)$, arroz $(4 \%)$, soja $(3 \%)$ e banana $(3 \%)$, que somam $74 \%$ do VBP. Ainda que esse cluster represente $14 \%$ dos estabelecimentos agropecuários brasileiros, $18 \%$ da área aproveitável para a agropecuária e $16 \%$ da mão de obra rural, ele é responsável por apenas $9 \%$ do PIB agropecuário, o que demonstra a baixa produtividade e baixa capacidade de geração de riqueza.

Os estabelecimentos possuem área de, em média, 79 hectares, valor bastante superior ao dos demais clusters com baixo nível de modernização. No entanto, com a baixa adoção de insumos e práticas modernas, a produção se caracteriza como extensiva, sobretudo no que diz respeito à agricultura, aproveitando-se apenas dos recursos disponíveis no solo e não realizando o seu uso de forma sustentável.

Os esforços realizados pelos produtores estão concentrados principalmente na criação de animais, com percentuais relativamente elevados de adoção de sal, ração e medicamentos (ver Apêndice). Além disso, a parcela de área de pastagem que é plantada é consideravelmente superior à média nacional. A agricultura, por outro lado, apresenta desempenho pífio, com pequenas parcelas de estabelecimentos que realizaram despesas com corretivos do solo, adubos, sementes e mudas, e defensivos, assim como baixos percentuais de estabelecimentos que adotaram práticas como o plantio direto, a rotação de cultura 
e o plantio em nível.

Dentre as principais carências do cluster 2, destacam-se o acesso restrito ao crédito, uma vez que apenas $13 \%$ dos estabelecimentos dos municípios, em média, obtiveram financiamentos em 2006. Além disso, o percentual de estabelecimentos que adota força mecânica é o menor dentre todos os clusters. Isso indica que, embora exista área agricultável disponível para esses produtores, a falta de recursos financeiros e técnicos é um gargalo importante para se ampliar as baixas produtividades e lucratividades apresentadas.

Dado o perfil voltado à criação de animais de grande porte do cluster 2, possíveis políticas voltadas a esses produtores devem ter como objetivo o incremento de produtividade na pecuária, aumentando as taxas de lotação de animais, realizando-se a recuperação de pastagens, garantindo a nutrição animal de qualidade e evitando a degradação das pastagens naturais. No que diz respeito à agricultura, tais políticas devem associar os estímulos econômicos à adoção de práticas sustentáveis no meio rural, visando manter/melhorar a qualidade dos solos, aumentar a eficiência produtiva e possibilitar uma maior agregação de renda para esses produtores que se encontram em condições adversas de produção.

O Cluster 3 é formado por 582 municípios, concentrados nas regiões Nordeste $(68 \%)$, sobretudo na Zona da Mata, e Sudeste (21\%), principalmente no Espírito Santo. Ele agrega $16 \%$ dos estabelecimentos agropecuários, $6 \%$ da área aproveitável para atividades agropecuárias do país e $18 \%$ do pessoal ocupado no meio rural. Embora o clima mais úmido característico desses municípios seja uma vantagem com relação ao semiárido brasileiro, o Cluster 3 demonstra relativo atraso na agropecuária, respondendo por apenas $11 \%$ do PIB agropecuário.

Esse cluster está associado a atividades mais intensivas em mão de obra, o que reduz o PIB por trabalhador $(\mathrm{R} \$ 9.107,06)$, mas aumenta a agregação de valor por hectare $(\mathrm{R} \$ 986,10)$. Além disso, por ser caracterizado pela grande quantidade de mão de obra, possíveis políticas direcionadas a esse cluster teriam efeito em uma parcela maior da sociedade.

A pauta produtiva está concentrada em 10 produtos, que são responsáveis por 70\% do seu Valor Bruto de Produção, conforme segue: Banana (13\%), Cana-de-açúcar (13\%), Mandioca (10\%), Café arábica (8\%), Horticultura (4\%), Laranja (3\%), Cacau (3\%), Criação de aves (7\%), Criação de animais de grande porte $(6 \%)$ e Ovos de galinha (3\%). Vários desses produtos podem ser comercializados diretamente ao consumidor final, como a banana, mandioca, laranja e produtos da horticultura, o que pode estar atrelado às cadeias curtas de comercialização e explicar o baixo nível de associação a cooperativas e entidades de classe.

O aumento dos níveis de mecanização é um dos aspectos que podem elevar a eficiência produtiva desses estabelecimentos. No entanto, a mecanização deve ser pensada de forma específica para esse grupo de produtores, uma vez que a produção é realizada em pequenos estabelecimentos (22 hectares, em média). Dessa forma, políticas que visem a melhoria das condições produtivas desse cluster passam pela criação de cooperativas e associações que permitam uma melhor organização da produção, eficiência em termos de mecanização, armazenamento e comercialização e maior difusão de conhecimento técnico, sobretudo no que diz respeito às boas práticas agrícolas.

A Figura 3 ilustra os Clusters 4, 5 e 6, isolados dos demais e, novamente, em ordem crescente de modernização. A Tabela 3, por sua vez, apresenta as 
características comuns dos clusters, 4, 5 e 6, bem como as especificidades de cada um que se destacam e outros indicadores relevantes para análise.

Figura 3: Clusters intermediários no processo de modernização

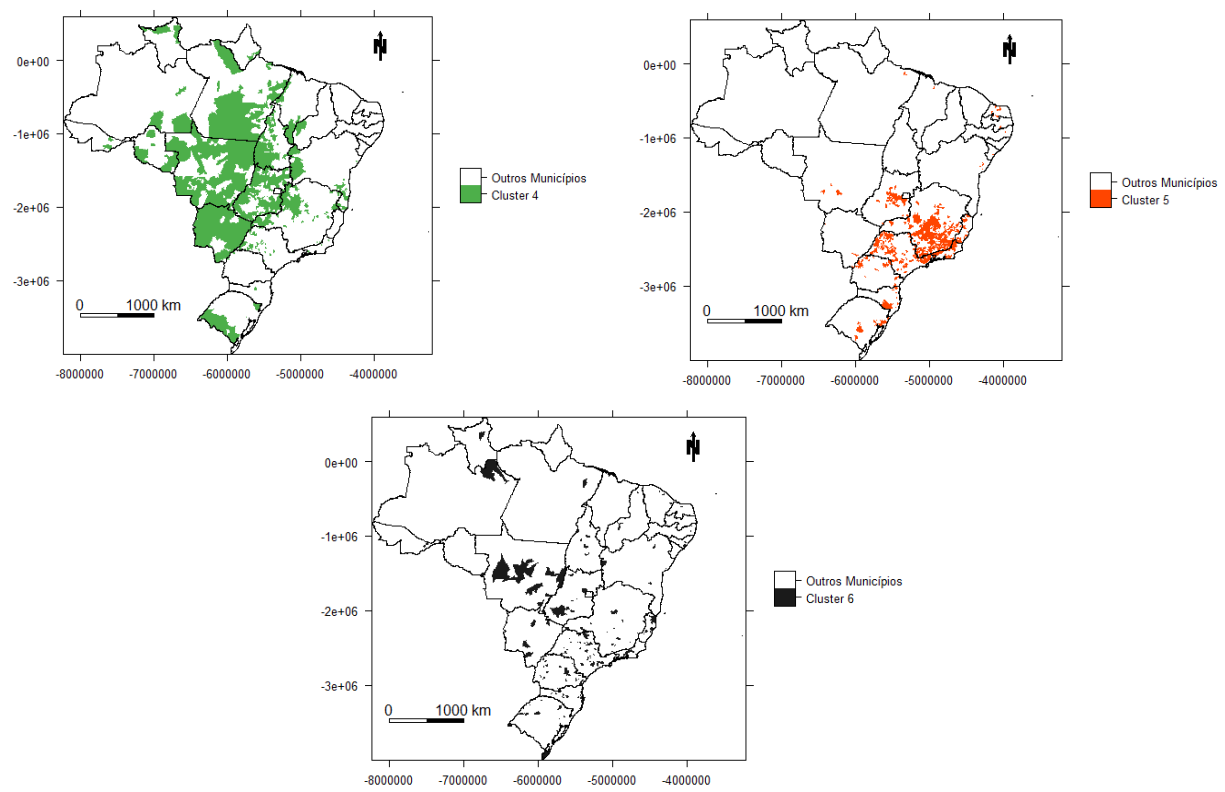

Fonte: Resultados da pesquisa.

Os clusters com níveis intermediários de modernização apresentam menos características em comum e são bastante dispersos regionalmente. Como aspectos comuns de destaque, os três clusters apresentam um nível relativamente elevado de escolaridade dos produtores e de orientação técnica recebida. No entanto, o acesso ao crédito ainda representa um gargalo para esses produtores, bem como os baixos níveis de cooperativismo.

O Cluster 4 é composto por 541 municípios, 49\% deles no Centro-Oeste, $20 \%$ no Sudeste (sobretudo na mesorregião Noroeste de Minas e Triângulo Mineiro) e $18 \%$ no Norte (principalmente nos estados do Tocantins e Pará). Nele se situam cerca de 375 mil estabelecimentos (7\% do total), que empregam $9 \%$ da mão de obra rural (802 mil trabalhadores em termos de EHA). Esses estabelecimentos são expressivamente maiores, atingindo, em média, os 317 hectares e respondem por $36 \%$ da área aproveitável para atividades agropecuárias e por $16 \%$ do PIB agropecuário.

Sua pauta produtiva é fortemente concentrada na criação de animais de grande porte $(41 \%)$ e produção de soja $(18 \%)$. Outras atividades com destaque são a produção de ccana-de-açúcar ( $8 \%$ ), leite de vaca, algodão, milho e silvicultura, cada um com $5 \%$ do total do VBP, e a criação de aves (3\%) e animais de médio porte (2\%). Todas essas atividades representam 92\% do valor de produção do Cluster 4 .

Com relação ao grau de capitalização e mecanização, apenas o número de tratores por EHA $(0,18$ - o que equivale a 1 trator para cada 6 trabalhadores) e o valor dos bens móveis por EHA $(\mathrm{R} \$ 24.982,25)$ são superiores às médias nacionais, classificando o nível de mecanização desse cluster como intermediário. 
Tabela 3: Principais características comuns e específicas dos clusters 4, 5 e 6

\begin{tabular}{|c|c|c|}
\hline \multicolumn{3}{|c|}{ Características comuns entre os clusters } \\
\hline \multicolumn{3}{|c|}{$\begin{array}{l}\text { - Índices relativamente altos de escolaridade e grau de orientação técnica recebido; } \\
\text { - Acesso ao crédito abaixo da média nacional; } \\
\text { - Baixos percentuais de associativismo e cooperativismo; } \\
\text { - Níveis intermediários de capitalização e mecanização; }\end{array}$} \\
\hline \multicolumn{3}{|c|}{ Características específicas de cada cluster } \\
\hline Cluster 4 & Cluster 5 & Cluster 6 \\
\hline $\begin{array}{l}\text { Elevada adoção de sal, } \\
\text { ração e medicamentos; }\end{array}$ & $\begin{array}{l}\text { Elevada adoção de cor- } \\
\text { retivos e adubos; }\end{array}$ & $\begin{array}{l}\text { Elevada adoção de cor- } \\
\text { retivos, adubos e de- } \\
\text { fensivos; }\end{array}$ \\
\hline $\begin{array}{l}\text { Elevado percentual de } \\
\text { pastagem plantada; }\end{array}$ & $\begin{array}{l}\text { Elevada adoção de sal } \\
\text { e ração, medicamentos } \\
\text { e suplementação; }\end{array}$ & $\begin{array}{l}\text { Uso intensivo da terra } \\
\text { com lavouras; }\end{array}$ \\
\hline $\begin{array}{l}\text { Baixa adoção de adu- } \\
\text { bos, corretivos, semen- } \\
\text { tes, mudas e defensi- } \\
\text { vos; }\end{array}$ & $\begin{array}{l}\text { Elevado percentual de } \\
\text { pastagem plantada }\end{array}$ & $\begin{array}{l}\text { Elevado grau de meca- } \\
\text { nização; }\end{array}$ \\
\hline \multirow[t]{2}{*}{$\begin{array}{l}\text { Baixa adoção de rota- } \\
\text { ção de cultura, plantio } \\
\text { direto e plantio em ní- } \\
\text { vel; }\end{array}$} & $\begin{array}{l}\text { Baixa adoção de defen- } \\
\text { sivos, sementes e mu- } \\
\text { das }\end{array}$ & $\begin{array}{l}\text { Elevada capacidade de } \\
\text { geração de renda por } \\
\text { hectare e por trabalha- } \\
\text { dor; }\end{array}$ \\
\hline & $\begin{array}{l}\text { Baixa adoção de rota- } \\
\text { ção de culturas e plan- } \\
\text { tio direto; }\end{array}$ & \\
\hline 541 municípios & 704 municípios & 224 municípios \\
\hline $\begin{array}{l}\text { Centro-Oeste, Noro- } \\
\text { este de Minas Gerais, } \\
\text { Triângulo Mineiro, } \\
\text { Tocantins e Pará }\end{array}$ & Sudeste e Sul & $\begin{array}{l}\text { Sudeste, Sul e Centro- } \\
\text { Oeste }\end{array}$ \\
\hline $\begin{array}{l}7 \% \text { dos estabelecimen- } \\
\text { tos }\end{array}$ & $\begin{array}{l}8 \% \text { dos estabelecimen- } \\
\text { tos }\end{array}$ & $\begin{array}{l}2 \% \text { dos estabelecimen- } \\
\text { tos }\end{array}$ \\
\hline $9 \%$ da mão de obra & $10 \%$ da mão de obra & $3 \%$ da mão de obra \\
\hline $\begin{array}{l}36 \% \text { da área agricultá- } \\
\text { vel }\end{array}$ & $\begin{array}{l}7 \% \text { da área agricultá- } \\
\text { vel }\end{array}$ & $\begin{array}{l}6 \% \text { da área agricultá- } \\
\text { vel }\end{array}$ \\
\hline $\begin{array}{l}16 \% \text { do PIB agropecuá- } \\
\text { rio }\end{array}$ & $\begin{array}{l}10 \% \text { do PIB agropecuá- } \\
\text { rio }\end{array}$ & $\begin{array}{l}11 \% \text { do PIB agropecuá- } \\
\text { rio }\end{array}$ \\
\hline $\begin{array}{l}\text { Animais de } \text { grande, } \\
\text { médio porte e aves, } \\
\text { soja, cana, leite, } \\
\text { algodão, milho, sil- } \\
\text { vicultura (92\% do } \\
\text { VBP) }\end{array}$ & $\begin{array}{l}\text { Animais de grande } \\
\text { porte e aves, leite, } \\
\text { ovos, café, cana, silvi- } \\
\text { cultura, milho, laranja } \\
\text { e horticultura ( } 81 \% \text { do } \\
\text { VBP) }\end{array}$ & $\begin{array}{l}\text { Soja, cana, milho, algo- } \\
\text { dão, animais (todos os } \\
\text { portes), ovos, leite, hor- } \\
\text { ticultura e silvicultura } \\
\text { ( } 87 \% \text { do VBP); }\end{array}$ \\
\hline $\begin{array}{l}\text { Área média: } 317 \text { hecta- } \\
\text { res }\end{array}$ & $\begin{array}{l}\text { Área média: } 50 \text { hecta- } \\
\text { res }\end{array}$ & $\begin{array}{l}\text { Área média: } 173 \text { hecta- } \\
\text { res }\end{array}$ \\
\hline
\end{tabular}

Fonte: Resultados da pesquisa. 
Com essa concentração de atividades ligadas à pecuária, variáveis como percentual de área de pastagem que é plantada (71\%) supera consideravelmente o valor médio nacional (50\%), assim como os percentuais de estabelecimentos que realizaram despesas com sal, ração e medicamentos para animais (ver Apêndice). As variáveis mais associadas à agricultura, por outro lado, apresentaram valores inferiores aos de referência, como os baixos percentuais de estabelecimentos que realizaram despesas com corretivos do solo, adubos, sementes e mudas e com defensivos. Além disso, a adoção de práticas como o plantio direto, plantio em nível e rotação de culturas é pouco presente nesse cluster.

Ainda que a pecuária seja prioridade nesse cluster, pode-se cconsiderá-la como uma atividade realizada de forma extensiva, dado o tamanho médio dos estabelecimentos e o baixo nível de agregação de valor por hectare (PIB agro/área agricultável). Assim, políticas direcionadas a esse cluster devem ter como principal direção o aumento da produtividade da pecuária, com renovação de pastagens, integração lavoura-pecuária e integração lavoura-pecuáriafloresta, evitando que essa extensa área ocupada por esses estabelecimentos seja degradada por práticas que não otimizem o uso dos recursos naturais. Além disso, a pecuária representa uma das atividades com maior potencial de efeito poupa-terra, por meio de aumentos na taxa de lotação de animais por hectare e por meio do aumento de peso-carcaça oriundo de melhores práticas de nutrição animal.

O Cluster 5 engloba 704 municípios, concentrados na região Sudeste $(81 \%)$, sobretudo no oeste paulista e na parcela central e sudeste de Minas Gerais, e na região Sul (10\%). Ao todo são 437 mil estabelecimentos ( $8 \%$ do total) que correspondem a $7 \%$ da área aproveitável para atividades agropecuárias no Brasil e a $10 \%$ do pessoal ocupado (896 mil trabalhadores), além de representar $10 \%$ do PIB agropecuário, demonstrando maior capacidade de agregação de valor do que os clusters analisados até então. Suas principais atividades são a criação de animais de grande porte $(23 \%)$, leite de vaca $(10 \%)$, a criação de aves $(10 \%)$, a produção de ovos de galinha (3\%), o cultivo de café $(10 \%)$, cana-de-açúcar $(9 \%)$, silvicultura (5\%), cultivo de milho $(5 \%)$, a horticultura (4\%) e a produção de laranja (3\%), totalizando $81 \%$ do VBP.

Ao contrário do Cluster 4, a adoção de corretivos do solo e adubos é relativamente elevada no Cluster 5 . Também são altos os percentuais de estabelecimentos que realizaram despesas com sal, ração, medicamentos e suplementação animal. Embora o grau de capitalização e mecanização seja próximo aos valores médios do Brasil, o acesso ao crédito é restrito, uma vez que apenas $13 \%$ dos estabelecimentos, em média, obteve financiamentos. Por se tratarem de estabelecimentos pequenos, com 50 hectares em média, a restrição de crédito pode representar uma barreira para o desenvolvimento das atividades.

Dadas as características do Cluster 5, políticas direcionadas a esses produtores devem possuir direcionamento similar às mencionadas para o Cluster 4 , no entanto, tendo em vista que a produção se dá em estabelecimentos muito menores. Regionalmente, grande parte dos municípios do Cluster 5 estão situados em importantes bacias leiteiras do Brasil, atividade com problemas conhecidos em termos de produtividade, sanidade, qualidade do leite, dentre outros. Dessa forma, políticas que auxiliem na profissionalização dos produtores de leite, em termos de manejo do rebanho, técnicas e equipamentos para armazenamento, nutrição e cuidados animais podem contribuir para a melhoria da qualidade do produto e para a geração de renda. 
O Cluster 6 é composto por 224 municípios, que situam 113 mil estabelecimentos ( $2 \%$ do total brasileiro), distribuídos nas regiões Sudeste (39\%), Sul (25\%) e Centro-Oeste (18\%). Os estabelecimentos possuem área média de 173 hectares e ocupam $6 \%$ da área aproveitável para atividades agropecuárias no Brasil. O pessoal ocupado nos estabelecimentos, cerca de 297 mil trabalhadores, representa 3\% do total. Apesar de pequenas parcelas em número de estabelecimentos, emprego e área, o Cluster 6 representa 11\% do PIB agropecuário brasileiro.

Nesse caso, ao contrário dos clusters 4 e 5, a produção está mais associada à agricultura, com uso intensivo do solo, bom aproveitamento de áreas agricultáveis com lavouras, elevado grau de mecanização, uso de insumos como adubos, corretivos, sementes, mudas e defensivos. O cluster possui alto grau de mecanização, com 1 trator para cada 4 trabalhadores (EHA), praticamente o dobro do valor médio nacional. Com relação às práticas de melhoramento do solo, destacam-se o uso de corretivos do solo, adubos e defensivos, insumos relativamente difundidos nesse cluster. Além disso, são altos os índices de escolaridade e de orientação técnica recebida pelos produtores (ver Apêndice).

Esse cluster possui alta capacidade de geração de riqueza, com um PIB/EHA da ordem de $\mathrm{R} \$ 48.581,67$ e um PIB/ha da ordem de $\mathrm{R} \$ 2.018,17$, ambos muito superiores às respectivas médias nacionais. A pauta produtiva se concentra na produção de soja, que representa $26 \%$ do VBP agropecuário, seguida pela cana-de-açúcar (15\%), milho (9\%), algodão (7\%). Somam-se, ainda, a criação de animais de grande porte $(9 \%)$, aves $(6 \%)$ e animais de médio porte $(2 \%)$, produção de ovos de galinha $(4 \%)$, leite de vaca $(2 \%)$, horticultura $(4 \%)$ e silvicultura (3\%). Juntos, esses produtos representam $87 \%$ do valor de produção.

Com relação ao direcionamento de políticas voltadas a esse perfil de produtor, devem ser considerados estímulos às práticas como rotação de culturas, plantio em nível e plantio direto, uma vez que, embora o cluster apresente indicadores próximos à média nacional, esses valores ainda são baixos e podem aumentar consideravelmente, evitando a degradação de áreas por uso intensivo e insustentável do solo e garantindo a continuidade das atividades.

A Figura 4 ilustra os três últimos clusters isolados dos demais e em ordem crescente de modernização. A Tabela 4, por sua vez, apresenta as características comuns dos clusters 7,8 e 9, bem como as especificidades de cada um que se destacam e outros indicadores relevantes para análise.

Os três clusters mais modernos identificados pela análise agregam municípios com características como o elevado grau de capitalização e mecanização, uso intensivo do solo, adoção de insumos modernos (corretivos, adubos, defensivos etc.) e práticas como o plantio em nível, rotação de culturas e plantio direto. Além disso, os estabelecimentos estão integrados ao mercado, são munidos de maior acesso ao crédito e maiores índices de orientação técnica, o que parece ser determinante para o bom desenvolvimento das atividades.

O Cluster 7 engloba 466 municípios, 63\% deles na região Sudeste (em grande parte do estado de São Paulo, sul de Minas Gerais e Triângulo Mineiro), 33\% na região Sul (sobretudo no Paraná) e uma pequena parcela no Centro Oeste. Possui cerca de 296 mil estabelecimentos agropecuários (6\% do total brasileiro), que ocupam $6 \%$ da área aproveitável para atividades agropecuárias no Brasil e possuem, em média, 66 hectares. Esses municípios empregaram $6 \%$ do pessoal ocupado em atividades agropecuárias (cerca de $790 \mathrm{mil}$ trabalhadores). Entretanto, o Cluster 7 é responsável por 16\% do PIB agropecuário, um salto expressivo com relação aos clusters analisados até então. 
Tabela 4: Principais características comuns e específicas dos clusters 7, 8 e 9

\author{
Características comuns entre os clusters \\ - Elevado grau de capitalização e mecanização; \\ - Uso intensivo do solo; \\ - Elevada adoção de sementes e mudas, corretivos, adubos e defensivos; \\ - Elevado grau de orientação técnica e escolaridade; \\ - Adoção de boas práticas: plantio em nível, rotação de culturas e plantio direto; \\ - Estabelecimentos integrados ao mercado; \\ - Acesso ao crédito acima da média nacional; \\ - Elevado uso de energia elétrica e combustíveis.
}

\begin{tabular}{|c|c|c|}
\hline \multicolumn{3}{|c|}{ Características específicas de cada cluster } \\
\hline Cluster 7 & Cluster 8 & Cluster 9 \\
\hline $\begin{array}{l}\text { Maior nível de integra- } \\
\text { ção ao mercado; }\end{array}$ & $\begin{array}{l}\text { Uso do solo menos in- } \\
\text { tensivo entre os clus- } \\
\text { ters modernos; }\end{array}$ & $\begin{array}{l}\text { Maiores graus de ca- } \\
\text { pitalização e mecaniza- } \\
\text { ção; }\end{array}$ \\
\hline $\begin{array}{l}\text { Pecuária é menos de- } \\
\text { senvolvida do que agri- } \\
\text { cultura; }\end{array}$ & $\begin{array}{l}\text { Elevada parcela de pas- } \\
\text { tagens naturais; }\end{array}$ & $\begin{array}{l}\text { Elevado acesso ao cré- } \\
\text { dito; }\end{array}$ \\
\hline $\begin{array}{l}\text { Uso muito intensivo do } \\
\text { solo; }\end{array}$ & $\begin{array}{l}\text { Baixo índice de com- } \\
\text { pra de animais; }\end{array}$ & $\begin{array}{l}\text { Alto percentual de coo- } \\
\text { perativismo e associati- } \\
\text { vismo; }\end{array}$ \\
\hline $\begin{array}{l}\text { Maior nível de escolari- } \\
\text { dade; }\end{array}$ & & $\begin{array}{l}\text { Elevada adoção de } \\
\text { energia elétrica e } \\
\text { combustíveis; }\end{array}$ \\
\hline 466 municípios & 373 municípios & 391 municípios \\
\hline $\begin{array}{l}\text { Sudeste (São Paulo, Sul } \\
\text { de Minas e Triângulo } \\
\text { Mineiro), Sul (Paraná) } \\
\text { e Centro-Oeste }\end{array}$ & Região Sul & Região Sul \\
\hline $\begin{array}{l}6 \% \text { dos estabelecimen- } \\
\text { tos }\end{array}$ & $\begin{array}{l}7 \% \text { dos estabelecimen- } \\
\text { tos }\end{array}$ & $\begin{array}{l}7 \% \text { dos estabelecimen- } \\
\text { tos }\end{array}$ \\
\hline $6 \%$ da mão de obra & $7 \%$ da mão de obra & $7 \%$ da mão de obra \\
\hline $\begin{array}{l}6 \% \text { da área agricultá- } \\
\text { vel }\end{array}$ & $\begin{array}{l}4 \% \text { da área agricultá- } \\
\text { vel }\end{array}$ & $\begin{array}{l}3 \% \text { da área agricultá- } \\
\text { vel }\end{array}$ \\
\hline $\begin{array}{l}16 \% \text { do PIB agropecuá- } \\
\text { rio }\end{array}$ & $\begin{array}{l}9 \% \text { do PIB agropecuá- } \\
\text { rio }\end{array}$ & $\begin{array}{l}7 \% \text { do PIB agropecuá- } \\
\text { rio }\end{array}$ \\
\hline $\begin{array}{l}\text { Cana, café, soja, ani- } \\
\text { mais de grande porte, } \\
\text { aves, leite, laranja, } \\
\text { milho, horticultura e } \\
\text { silvicultura ( } 88 \% \text { do } \\
\text { VBP) }\end{array}$ & $\begin{array}{l}\text { Fumo, soja, animais } \\
\text { de grande porte, mi- } \\
\text { lho, arroz, aves, sil- } \\
\text { vicultura, animais de } \\
\text { médio porte, leite e } \\
\text { horticultura ( } 81 \% \text { do } \\
\text { VBP) }\end{array}$ & $\begin{array}{l}\text { Soja, milho, animais de } \\
\text { grande e médio porte, } \\
\text { aves, leite, ovos, mi- } \\
\text { lho forrageiro, fumo e } \\
\text { trigo }(91 \% \text { do VBP })\end{array}$ \\
\hline $\begin{array}{l}\text { Área média: } 66 \text { hecta- } \\
\text { res }\end{array}$ & $\begin{array}{l}\text { Área média: } 36 \text { hecta- } \\
\text { res }\end{array}$ & $\begin{array}{l}\text { Área média: } 25 \text { hecta- } \\
\text { res }\end{array}$ \\
\hline
\end{tabular}

Fonte: Resultados da pesquisa. 
Figura 4: Clusters mais avançados no processo de modernização
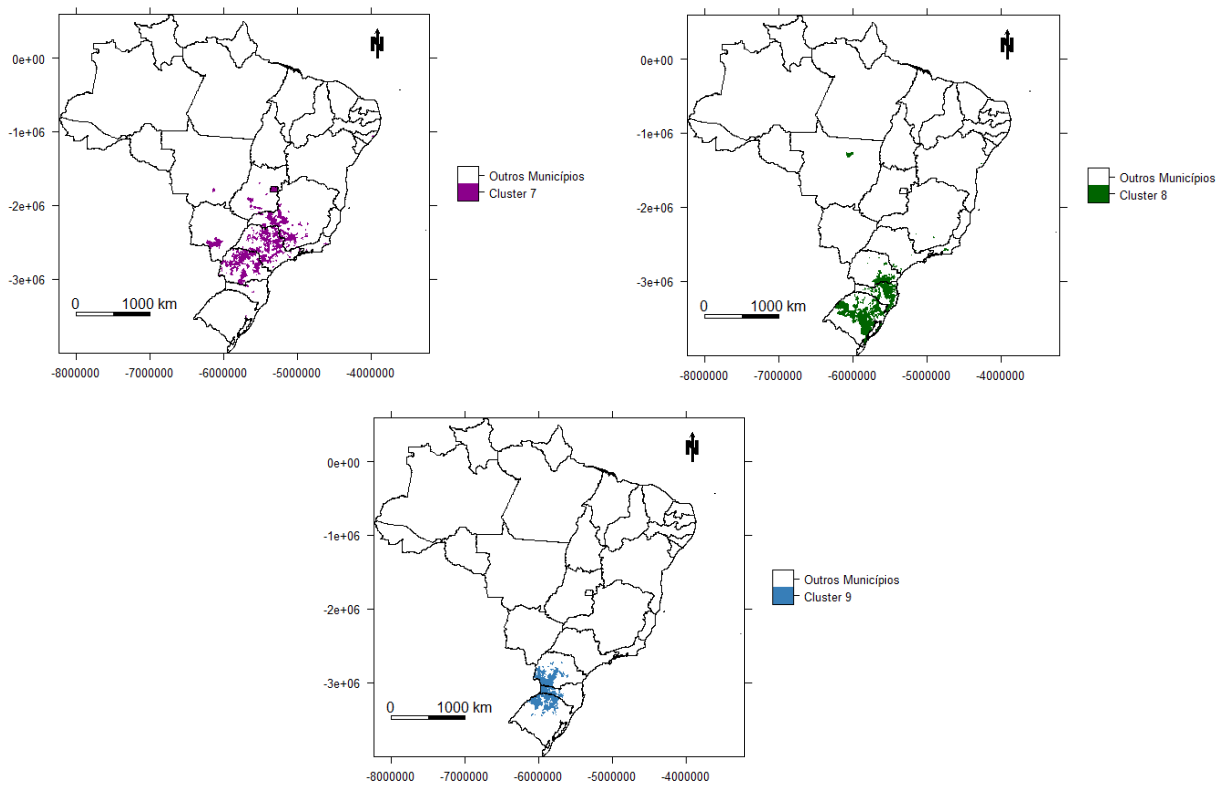

Fonte: Resultados da pesquisa.

As variáveis com ligação direta com a agricultura, como o uso de corretivos, adubos, sementes, mudas e defensivos apresentaram valores consideravelmente maiores que as médias nacionais, ainda que as atividades se desenvolvam em estabelecimentos relativamente pequenos, com 66 hectares, em média. Além disso, grande parte da área agricultável é ocupada com lavouras permanentes e temporárias.

São elevados os índices de escolaridade e de orientação técnica, o que contribui para uma maior difusão da adoção de práticas como o plantio em nível e o plantio direto. O Cluster 7 apresentou o maior índice de integração ao mercado $(0,69)$ e um percentual de estabelecimentos que obteve financiamentos pouco superior à média nacional. Como resultante, a capacidade de geração de renda desse cluster é consideravelmente alta (ver Apêndice).

Por outro lado, a parcela de estabelecimentos que realizou despesas com sal e ração, medicamentos e suplementação animal, apresentaram valores similares aos de referência, demonstrando o maior avanço da agricultura neste cluster. Sua pauta produtiva é concentrada em atividades como a cana-deaçúcar, com $27 \%$ do total do VBP, seguida pelo café (13\%), soja (11\%), animais de grande porte $(9 \%)$, de aves $(6 \%)$, leite de vaca $(3 \%)$, laranja $(7 \%)$, milho $(7 \%)$, horticultura (3\%) e silvicultura (2\%), que totalizam $88 \%$ do VBP.

O Cluster 8, por sua vez, é composto por 373 municípios, concentrados na região Sul (97\%), ao leste do Paraná e Santa Catarina (mesorregiões Metropolitana de Curitiba, Sudeste Paranaense, Norte e Sul Catarinenses, Grande Florianópolis e Vale do Itajaí) e nas mesorregiões Centro-Ocidental, CentroOriental, Nordeste e Sudeste Riograndense. Esses municípios ocupam 4\% da área aproveitável para atividades agropecuárias no país, na qual estão situados aproximadamente 342 mil estabelecimentos agropecuários (7\% do total), com área média de 36 hectares. O cluster é responsável por 7\% do pessoal ocupado, 626 mil trabalhadores e por 9\% do PIB agropecuário. 
O cluster 8 é caracterizado pelo alto nível de capitalização e mecanização, integração ao mercado, acesso ao crédito e adoção de insumos e práticas modernas, embora o desempenho em variáveis mais relacionadas à pecuária seja inferior às médias nacionais, com uso mais extensivo do solo em um maior percentual de pastagens naturais. No caso das variáveis mais associadas à agricultura, destaca-se a adoção de insumos como corretivos do solo, adubos, sementes e mudas e defensivos, com percentuais de adoção superiores às respectivas médias nacionais, bem como a adoção de práticas como o plantio direto na palha, a rotação de culturas, o plantio em nível e os elevados índices de escolaridade e de orientação técnica.

Esse cluster possui elevado índice de integração ao mercado e acesso ao crédito, além de $53 \%$ dos estabelecimentos, em média, associados às cooperativas ou entidades de classe. Sua pauta de produção possui como principal representante o fumo, que responde por $15 \%$ do VBP, seguido pela soja $(11 \%)$, animais de grande porte $(10 \%)$, milho $(9 \%)$, arroz $(8 \%)$, aves, silvicultura $(8 \%)$, animais de médio porte $(6 \%)$, leite de vaca (4\%) e horticultura (3\%), totalizando $81 \%$ do valor de produção agropecuário.

Por fim, o Cluster 9 é composto por 391 municípios, todos situados na região Sul, englobando a parcela sudoeste do Paraná, o Oeste Catarinense e o Noroeste Riograndense. São cerca de 365 mil estabelecimentos (7\% do total brasileiro), que ocupam 3\% da área aproveitável para atividades agropecuárias no Brasil, respondem por 7\% do pessoal ocupado (cerca de $655 \mathrm{mil}$ empregos) e 7\% do PIB agropecuário.

Esse cluster é composto por estabelecimentos com alto grau de capitalização e mecanização, bem como o maior percentual de acesso ao crédito, uma vez que $52 \%$ de seus estabelecimentos obtiveram financiamentos em 2006, contra 19\% que representa o valor médio nacional. É elevado também o percentual de estabelecimentos associados a cooperativas e entidades de classe (71\%) e com baixo nível de especialização, demonstrando uma relação entre a diversificação produtiva e a geração de riqueza.

A adoção de insumos e práticas modernas, como corretivos, adubos, defensivos, plantio em nível, rotação de culturas e plantio direto, está presente na maioria desses estabelecimentos, sobretudo no que diz respeito à agricultura. É também elevado o índice de orientação técnica recebida pelos produtores $(0,42$ contra 0,22 da média nacional).

A pauta produtiva do Cluster 9 é composta pela produção de soja (20\%), milho $(13 \%)$, animais de grande porte $(14 \%)$, de médio porte $(13 \%)$, aves $(11 \%)$, leite de vaca $(8 \%)$ e ovos de galinha $(4 \%)$, milho forrageiro $(3 \%)$, fumo $(3 \%)$ e trigo $(2 \%)$. Essas atividades representam, juntas, $91 \%$ do VBP.

Para os casos dos clusters 7, 8 e 9, que se destacam pelos mais altos níveis de modernização agropecuária do país, o direcionamento de políticas públicas se dá de forma pontual, visando mitigar eventuais ineficiências que ocorram em algum desses clusters, como o baixo percentual de pastagens plantadas, o estímulo ao plantio direto e à rotação de culturas. Esses clusters são bons exemplos para ilustrar que as políticas visando a redução de disparidades no meio rural, o desenvolvimento e integração de produtores com maiores vulnerabilidades produtivas e econômicas deve se dar por múltiplos fatores combinados, de forma a prover as condições necessárias para que esses produtores se insiram no processo de modernização.

Em suma, os 9 clusters descritos neste trabalho demonstram o avanço das regiões Sul e Sudeste no processo de modernização. Essas regiões, além de 
apresentarem condições estruturais relativamente favoráveis à agropecuária, como clima, fertilidade do solo e infraestrutura logística, contam também com os maiores níveis de acesso ao crédito, capitalização, capacitação e orientação técnica dos produtores. Isso destaca o importante papel de institutos de pesquisa e extensão como a Embrapa, Emater e escolas agrícolas, na geração e difusão do conhecimento técnico e científico para os produtores rurais das regiões menos modernas. Políticas que estimulem a difusão da pesquisa e extensão podem, em conjunto com outros instrumentos, como políticas bem direcionadas de concessão de crédito rural, garantia de demanda e seguro agrícola, minimizar o abismo existente entre o moderno e o arcaico na agropecuária brasileira.

Do ponto de vista das culturas, este texto demonstra que mesmo em casos de culturas mais integradas ao mercado, como a cana-de-açúcar, milho, pecuária bovina e criação de aves, o processo de modernização se deu de forma diferenciada entre produtores, uma vez que essas atividades coexistem nos mais diversos padrões tecnológicos, sejam eles avançados (clusters 7,8 e 9), intermediários (clusters 4, 5 e 6) ou atrasados (clusters 1, 2 e 3). Isso permite dizer que políticas de modernização que levem em consideração tanto as atividades produtivas/culturas, quanto o perfil e as condições regionais dos produtores são uma estratégia imprescindível para se buscar o aumento da produtividade no campo e a equalização produtiva.

O pacote de modernização cumpriu e vem cumprindo uma de suas funções, de transformar o Brasil em um dos principais players mundiais do agronegócio. No entanto, ainda é necessário repartir os benefícios dessa modernização e fornecer as condições necessárias para que os produtores viabilizem seus empreendimentos e melhorem seus níveis de desenvolvimento e condições de vida. Para tal, um novo "pacote modernizante" deveria basear-se na difusão de conhecimento técnico, na capacitação e na capitalização dos produtores rurais considerando as especificidades regionais de cada grupo, sobretudo dos mais vulneráveis que, a grosso modo, se situam no sertão nordestino e em partes da região Norte. Não basta apenas terra (reforma agrária) e crédito. Essas são condições necessárias, mas não suficientes para a ascensão de grande parte dos produtores rurais brasileiros.

As recomendações realizadas ao longo deste trabalho não têm por objetivo representar um pacote pronto de políticas de modernização e inclusão produtiva e nem mesmo esgotar as possibilidades. Por meio delas, pretende-se estimular o debate com relação ao tema, destacando os diferentes perfis de produtores rurais existentes no Brasil e suas principais carências em termos produtivos e econômicos.

\section{Considerações finais}

O presente estudo construiu grupos homogêneos de municípios com relação aos seus indicadores de modernização agropecuária no ano de 2006. Os 9 clusters resultantes do trabalho corroboram parcialmente a literatura ao indicar a maior concentração de municípios com agropecuária moderna na região Centro-Sul e municípios com maiores vulnerabilidades econômico-produtivas nas regiões Nordeste e Norte. Todavia, o trabalho destaca a forte heterogeneidade intrarregional, sob a qual coexistem, dentro de uma mesma unidade da federação, graus bastante distintos de modernização entre seus municípios. 
Os três clusters menos modernos representam 54\% dos estabelecimentos agropecuários brasileiros, $56 \%$ do pessoal ocupado e 32\% da área aproveitável para atividades agropecuárias no país. Ainda assim, representam apenas $25 \%$ do PIB agropecuário brasileiro, o que demonstra a precariedade de condições produtivas e estruturais, a vulnerabilidade econômica enfrentada por esses produtores e sua consequente incapacidade de geração de renda. Com toda essa representatividade, maior atenção deve ser dada a esses grupos, visando garantir condições mínimas de produção e reprodução no meio rural, de forma a mitigar problemas posteriores, como o êxodo rural e marginalização dessas pessoas nos centros urbanos e a dificuldade de sucessão familiar no meio rural.

Os clusters de municípios "arcaicos" e, portanto, mais vulneráveis se concentram no Nordeste em parcelas da região Norte, onde são encontradas condições relativamente desfavoráveis à produção agropecuária. Ainda que tenham sido realizados programas de redistribuição de terras e de apoio à agricultura familiar a partir de meados dos anos 1990 (Helfand \& Rezende 2001), a falta de difusão do conhecimento e da adequação técnica e tecnológica às especificidades regionais impede que os benefícios da modernização, que tornou o Brasil um dos principais players do agronegócio mundial, cheguem a todos os produtores rurais brasileiros, ampliando o hiato econômico, tecnológico e produtivo entre eles.

\section{Referências Bibliográficas}

Almeida, J. (1997). Da ideologia do progresso à ideia de desenvolvimento rural sustentável. In: ALMEIDA, J.; NAVARRO, Z. (orgs.) Reconstruindo a agricultura: ideias e ideais na perspectiva do desenvolvimento rural sustentável. Porto Alegre: Editora da Universidade (UFRGS). p. 33-55.

Bacha, C. J. C. (2004). Economia e Política Agrícola no Brasil. 1. ed. São Paulo: Atlas.

Balsan, R. (2006). Impactos decorrentes da modernização da agricultura brasileira. Campo-Território: Revista de Geografia Agrária, Uberlândia, v. 1, n. 2, p. 123-151.

Banfield, J. D. \& Raftery, A. E. (1992). Ice floe identification in satellite images using mathematical morphology and clustering about principal curves. Journal of the American Statistical Association, Washington, v. 87, n. 417, p. 7-16.

Bock, H. H. (1996). Probabilistic Models in Cluster Analysis. Computational Statistics and Data Analysis, Amsterdam, v. 23, n. 1, p. 5-28.

Buainain, A. M. (1999). Trajetória recente da política agrícola brasileira. 1999. Tese (Doutorado em Ciências Econômicas) - Instituto de Economia, Universidade Estadual de Campinas, Campinas, 1999. Disponível em: http://repositorio.unicamp.br/jspui/handle/REPOSIP/285712. Acesso em: 28 fev. 2017.

Campos, S. A. C., Pereira, M. W. G. \& Teixeira, E. C. (2014). Trajetória de modernização da agropecuária mineira no período de 1996 a 2006. Economia Aplicada, Ribeirão Preto, v. 18, n. 4, p. 717-739. 
Celeux, G. \& Govaert, G. (1992). A classification EM algorithm for clustering for two sthocastic versions. Computational Statistics e Data Analysis, Amsterdam, v. 14, n. 3, p. 315-332.

Cruz, F. O., Ribeiro, C. G. \& Lima, I. B. (2006). A modernização agrícola nos municípios da mesorregião Campo das Vertentes: uma aplicação de métodos de análise multivariada. XLIV Congresso da SOBER, Fortaleza.

Delgado, G. C. (2012). Institutions, freedom, and technical efficiency. O que significa a economia política do agronegócio no Brasil atual (anos 2000). Disponível em: https://agroecologia.org.br/2013/12/10/delgado-projeto-doagronegocio-seria-impensavel-numa-democracia-real/. Acesso em: 05 ago. 2018.

Do, C. B. \& Serafim, B. (2008). What is the expectation maximization algorithm?. Nature Biotechnology, New York, v. 26, n. 8, p. 897-899.

Duran, B. S. \& Odell, P. L. (1974). Cluster Analysis: a Survey. Berlin: Springer.

Ferreira, S., Baptista, A. J. M. S. \& Lima, J. E. (2004). A modernização agropecuária nas microrregiões do estado de Minas Gerais. Revista de Economia e Sociologia Rural, Brasília, v. 42, n. 1, p. 73-89.

Fraley, C. \& Raftery, A. E. (2002). Model-based clustering, discriminant analysis and density estimation. Journal of the American Statistical Association, Washington, v. 97, n. 458, p. 611-631.

Gasques, J. G. (2010). Produtividade total dos fatores e transformações da agricultura brasileira: análise dos dados dos Censos Agropecuários. In: GASQUES, J. G.; VIEIRA FILHO, J. E.; BACCHI, M. R. P.; VALDES, C. (orgs.) Agricultura brasileira: desempenho, desafios e perspectivas. Brasília: Instituto de Pesquisa Econômica Aplicada (IPEA). v. 1, cap. 1, p. 19-44.

Gonzalez, B. C. R. \& Costa, S. M. A. L. (1998). Agricultura brasileira: modernização e desempenho. Teoria e Evidência Econômica, Passo Fundo, v. 5, n. 7, p. 7-35.

Hair, J. F., Anderson, R. E., Tatham, R. L. \& Black, W. C. (2009). Multivariate Data Analysis. New Jersey: Prentice Hall.

Helfand, S. M. \& Rezende, G. C. (2001). Brazilian agriculture in the 1990s: impact of the policy reforms. Rio de Janeiro: IPEA, 2001. (Texto para discussão, n. 785).

Hoffmann, R. (1992). A dinâmica da modernização da agricultura e distribuição da renda em 157 microrregiões homogêneas do Brasil. Piracicaba: ESALQ.

Hoffmann, R. \& Kageyama, A. (1985). Modernização da agricultura e distribuição de renda no Brasil. Pesquisa e Planejamento Econômico, Rio de Janeiro, v. 15, n. 1, p. 171-208.

Hoffmann, R. \& Kassouf, A. L. (1989a). Produção e modernização e agropecuária em 332 microrregiões homogêneas do Brasil - 1980. Piracicaba: ESALQ. 
Hoffmann, R. \& Kassouf, A. L. (1989b). Modernização e desigualdade na agricultura brasileira. Revista Brasileira de Economia, Rio de Janeiro, v. 43, n. 2, p. 273-303.

IBGE - Instituto Brasileiro de Geografia e Estatística (2009). Censo Agropecuários 2006. Rio de Janeiro: IBGE. Disponível em: https://sidra.ibge.gov.br/home/pimpfbr/brasil. Acesso em: 10 jan. 2017.

Johnson, R. A. \& Wichern, D. W. (2007). Applied Multivariate Statistical Analysis. New Jersey: Prentice Hall.

Kageyama, A. (1986). Problemas Metodológicos na Mensuração do Emprego Agrícola. Campinas: Instituto de Economia, UNICAMP.

Kageyama, A. (1990). O Novo padrão agrícola brasileiro: do complexo rural aos complexos agroindustriais. In: DELGADO, G. C.; GASQUES, J. G.; VILA VERDE, C. M. (orgs.) Agricultura e Políticas Públicas. Brasília: IPEA. cap. 11, p. 113-223.

Kageyama, A., Bergamasco, S. M. P. P. \& Oliveira, J. A. (2014). Uma classificação dos estabelecimentos agropecuários do Brasil a partir do Censo de 2006. In: SCHNEIDER, S.; FERREIRA, B.; ALVES, F. (orgs.) Aspectos Multidimensionais da Agricultura Arasileira. Brasília: IPEA. p. 21-40.

Kassambara, A. (2017). Practical Guide to Cluster Analysis in R. [S.1.]: STHDA.

Kaufman, L. \& Rousseeuw, P. J. (1990). Finding Groups in Data: an Introduction to Cluster Analysis. New York: Wiley.

Lawson, R. G. \& Jurs, P. C. (1990). New index for clustering tendency and its application to chemical problems. Journal of Chemical Information and Computer Sciences, Washington, v. 30, n. 1, p. 36-41.

Llanilo, R. F., Del Grossi, M. E., Santos, F. O., Munhos, P. D. \& Guimarães, M. F. (2006). Regionalização da agricultura do estado do Paraná, Brasil. Ciência Rural, Santa Maria, v. 36, n. 1, p. 120-127.

Martine, G. (1991). A trajetória da modernização agrícola: a quem beneficia? Lua Nova, São Paulo, v. 1, n. 23, p. 7-37.

Martine, G. \& Garcia, R. C. (1987). Os Impactos Sociais da Modernização Agrícola. São Paulo: Caetes.

Mclachlan, G. J. \& Basford, K. E. (1988). Mixture Models Inference and Applications to Clustering. New York: Marcel Dekker.

Melnykov, V. \& Maitra, R. (2010). Finite mixture models and model-based clustering. Statistics Surveys, v. 4, n. 1, p. 80-116.

Murtagh, F. \& Raftery, A. E. (1984). Fitting straight lines to point patterns. Pattern Recognition, Amsterdam, v. 17, n. 5, p. 479-483.

Paz, M. V., Freitas, C. A. \& Nicola, D. S. (2006). Avaliando a intensidade da modernização da agropecuária gaúcha: uma aplicação de análise fatorial e cluster. XLIV Congresso da SOBER, Fortaleza. 
Rezende, G. C. (2006). Políticas trabalhista, fundiária e de crédito agrícola no Brasil: uma avaliação crítica. Revista de Economia e Sociologia Rural, Brasília, v. 44, n. 1 , p. $47-78$.

Scrucca, L. F. M., Murphy, T. B. \& Raftery, A. E. (2016). Mclust 5: clustering, classification and density estimation using Gaussian finite mixture models. The R Journal, Vienna, v. 8, n. 1, p. 205-233.

Silva, G. B. \& Botelho, M. I. V. (2014). O processo histórico da modernização da agricultura no Brasil (1960-1979). Campo-Território: Revista de Geografia Agrária, Uberlândia, v. 9, n. 17, p. 362-387.

Silva, J. G. (1996). A Nova Dinâmica da Agricultura Brasileira. Campinas: Unicamp.

Silva, J. G. \& Kageyama, A. (1983). Emprego e relações de trabalho na agricultura brasileira: uma análise dos dados censitários de 1960, 1970, e 1975. Pesquisa e Planejamento Econômico, Rio de Janeiro, v. 13, n. 1, p. 235-266.

Silva, J. G., Kageyama, A., Romão, D. A., Wagner Neto, J. A. \& Pinto, L. C. G. (1983). Tecnologia e campesinato: o caso brasileiro. Revista de Economia Política, São Paulo, v. 3, n. 4, p. 21-56.

Souza, P. M. \& Lima, J. E. (2003). Intensidade e dinâmica da modernização agrícola no Brasil e nas Unidades da Federação. Revista Brasileira de Economia, Rio de Janeiro, v. 57, n. 4, p. 795-824.

Souza, R. F. \& Khan, A. S. (2001). A modernização da agricultura, classificação dos municípios e concentração da terra no estado do Maranhão. Revista Econômica do Nordeste, Fortaleza, v. 32, n. 1, p. 96-111.

Wedekin, I. (2005). A política agrícola brasileira em perspectiva. Revista de Política Agrícola, Brasília, Edição Especial, p. 17-32. 


\section{Apêndice A}

Tabela A.1: Médias dos indicadores de modernização por Cluster e indicadores correlatos

\begin{tabular}{|c|c|c|c|c|c|c|c|c|c|c|}
\hline \multirow{2}{*}{ Variáveis } & \multicolumn{9}{|c|}{ Média do Cluster } & \multirow{2}{*}{$\begin{array}{r}\text { Média } \\
\text { Geral }\end{array}$} \\
\hline & 1 & 2 & 3 & 4 & 5 & 6 & 7 & 8 & 9 & \\
\hline \multicolumn{11}{|l|}{ Lucratividade } \\
\hline X16 - PIB agro/EHA; & 2,99 & 6,99 & 9,11 & 22,30 & 13,16 & 48,58 & 26,54 & 17,26 & 12,83 & 14,88 \\
\hline X15 - PIB agro/AA; & 0,25 & 0,19 & 0,99 & 0,20 & 0,55 & 2,02 & 1,13 & 1,22 & 1,00 & 0,70 \\
\hline \multicolumn{11}{|l|}{ Capitalização } \\
\hline $\mathrm{X} 5-\mathrm{N}^{\circ}$ de tratores/EHA; & 0,01 & 0,03 & 0,02 & 0,18 & 0,12 & 0,24 & 0,25 & 0,24 & 0,17 & 0,12 \\
\hline X13 - $\$$ bens móveis/EHA; & 4,34 & 14,46 & 4,91 & 65,81 & 21,63 & 77,53 & 26,46 & 24,98 & 23,19 & 24,98 \\
\hline X12 - $\$$ bens móveis/AL; & 0,41 & 0,47 & 0,61 & 0,67 & 1,02 & 2,58 & 1,26 & 1,97 & 2,00 & 1,03 \\
\hline X6 - Máquinas e implementos/EHA; & 0,29 & 0,12 & 0,14 & 0,58 & 0,63 & 0,76 & 0,90 & 1,22 & 1,37 & 0,59 \\
\hline X1 - Est. força mecânica/TE; & 0,25 & 0,19 & 0,22 & 0,34 & 0,37 & 0,49 & 0,60 & 0,55 & 0,65 & 0,37 \\
\hline X21 - Est. compra animais/TE; & 0,24 & 0,21 & 0,17 & 0,23 & 0,22 & 0,21 & 0,18 & 0,38 & 0,53 & 0,25 \\
\hline \multicolumn{11}{|l|}{ Especialização/diversificação } \\
\hline X27-Est. muito especializados/TE; & 0,14 & 0,21 & 0,31 & 0,27 & 0,28 & 0,34 & 0,34 & 0,15 & 0,09 & 0,23 \\
\hline X28 - Est. especializados/TE; & 0,36 & 0,37 & 0,34 & 0,41 & 0,38 & 0,35 & 0,33 & 0,44 & 0,34 & 0,37 \\
\hline \multicolumn{11}{|l|}{ Integração } \\
\hline X30 - Indice de integração; & 0,47 & 0,50 & 0,63 & 0,59 & 0,59 & 0,66 & 0,69 & $\overline{0,61}$ & 0,62 & 0,59 \\
\hline X7 - Est. financiamentos/TE; & 0,16 & 0,13 & 0,12 & 0,14 & 0,13 & 0,18 & 0,21 & 0,30 & 0,52 & 0,19 \\
\hline X29 - Est. cooperativas/TE; & 0,44 & 0,37 & 0,32 & 0,31 & 0,31 & 0,37 & 0,40 & 0,53 & 0,71 & 0,40 \\
\hline \multicolumn{11}{|l|}{ Intensividade do uso do solo } \\
\hline X4-Área com lavouras/AA; & 0,17 & 0,07 & 0,37 & 0,09 & 0,15 & $\overline{0,37}$ & 0,49 & 0,35 & 0,53 & 0,26 \\
\hline X18 - Est. corretivos/TE; & 0,1 & 0,03 & 0,10 & 0,10 & 0,21 & 0,22 & 0,27 & 0,19 & 0,11 & 0,13 \\
\hline X17 - Est. adubos/TE; & 0,05 & 0,12 & 0,36 & 0,20 & 0,43 & 0,45 & 0,60 & 0,67 & 0,79 & 0,37 \\
\hline X19-Est. sementes/TE; & 0,05 & 0,09 & 0,08 & 0,10 & 0,15 & 0,19 & 0,24 & 0,36 & 0,51 & 0,17 \\
\hline X14 - Est. sal ração/TE; & 0,30 & 0,44 & 0,15 & 0,61 & 0,56 & 0,38 & 0,39 & 0,45 & 0,65 & 0,43 \\
\hline X20 - Est. agrotóxicos/TE; & 0,25 & 0,13 & 0,22 & 0,13 & 0,20 & 0,36 & 0,49 & 0,60 & 0,77 & 0,31 \\
\hline X22 - Est. medicamentos anim./TE; & 0,52 & 0,66 & 0,32 & 0,80 & 0,72 & 0,55 & 0,55 & 0,68 & 0,77 & 0,62 \\
\hline X26-Suplementação animal; & 0,63 & 0,55 & 0,56 & 0,59 & 0,66 & 0,63 & 0,65 & 0,65 & 0,68 & 0,62 \\
\hline X2 - Área pastagem plantada/AP; & 0,28 & 0,71 & 0,47 & 0,71 & 0,53 & 0,50 & 0,57 & 0,22 & 0,42 & 0,50 \\
\hline X3 - Área trabalhada/AA; & 0,29 & 0,46 & 0,55 & 0,53 & 0,49 & 0,54 & 0,68 & 0,40 & 0,63 & 0,50 \\
\hline \multicolumn{11}{|l|}{ Técnicas } \\
\hline$\overline{\mathrm{X} 10 \text { - Est. plantio direto /TE; }}$ & 0,03 & $\overline{0,06}$ & 0,03 & 0,03 & 0,02 & $\overline{0,13}$ & 0,18 & 0,21 & 0,65 & $\overline{0,13}$ \\
\hline X25 - Orientação técnica; & 0,07 & 0,09 & 0,10 & 0,22 & 0,24 & 0,32 & 0,40 & 0,36 & 0,42 & 0,22 \\
\hline X11 - Est. rotação de cultura/TE; & 0,06 & 0,08 & 0,10 & 0,04 & 0,07 & 0,16 & 0,15 & 0,29 & 0,49 & 0,14 \\
\hline X24 - Escolaridade do dirigente; & 0,24 & 0,32 & 0,33 & 0,47 & 0,50 & 0,50 & 0,55 & 0,46 & 0,45 & 0,41 \\
\hline X9 - Est. plantio em nível/TE; & 0,27 & 0,16 & 0,34 & 0,17 & 0,35 & 0,39 & 0,53 & 0,38 & 0,44 & 0,32 \\
\hline \multicolumn{11}{|l|}{ Energia } \\
\hline X23-Est. energia elétrica/TE; & 0,70 & 0,56 & 0,70 & 0,70 & 0,85 & 0,82 & 0,77 & 0,91 & 0,86 & 0,75 \\
\hline X8 - Est. combustíveis/TE; & 0,50 & 0,49 & 0,38 & 0,54 & 0,43 & 0,47 & 0,53 & 0,60 & 0,72 & 0,51 \\
\hline \multicolumn{11}{|l|}{ Correlatos } \\
\hline PIB agropecuário (\%) & $5 \%$ & $9 \%$ & $11 \%$ & $16 \%$ & $10 \%$ & $11 \%$ & $16 \%$ & $9 \%$ & $7 \%$ & \\
\hline Estabelecimentos (\%) & $23 \%$ & $14 \%$ & $16 \%$ & $7 \%$ & $8 \%$ & $2 \%$ & $6 \%$ & $7 \%$ & $7 \%$ & - \\
\hline Área (\%) & $8 \%$ & $18 \%$ & $6 \%$ & $36 \%$ & $7 \%$ & $6 \%$ & $6 \%$ & $4 \%$ & $3 \%$ & - \\
\hline Mão de obra (\%) & $22 \%$ & $16 \%$ & $18 \%$ & $9 \%$ & $10 \%$ & $3 \%$ & $8 \%$ & $7 \%$ & $7 \%$ & - \\
\hline Municípios (unidades) & 653 & 601 & 582 & 541 & 704 & 224 & 466 & 373 & 391 & - \\
\hline Área média (hectares) & 24 & 79 & 22 & 317 & 50 & 173 & 66 & 36 & 25 & - \\
\hline
\end{tabular}

Fonte: Elaborado pelo autor. 
